\title{
Efficient Firm Dynamics in a Frictional Labor Market*
}

\author{
Leo Kaas ${ }^{\dagger} \quad$ Philipp Kircher ${ }^{\ddagger}$
}

\begin{abstract}
We develop and analyze a labor market model in which heterogeneous firms operate under decreasing returns and compete for labor by posting long-term contracts. Firms achieve faster growth by offering higher lifetime wages, which allows them to fill vacancies with higher probability, consistent with recent empirical findings. The model also captures several other regularities about firm size, job flows and pay, and generates sluggish aggregate dynamics of labor market variables. In contrast to existing bargaining models with large firms, efficiency obtains and the model allows a tractable characterization over the business cycle.
\end{abstract}

JEL classification: E24; J64; L11

Keywords: Labor market search, multi-worker firms, job creation and job destruction

\section{DECEMBER 3, 2014}

${ }^{*}$ We thank Rüdiger Bachmann, Matthieu Bellon, Steven Davis, Jan Eeckhout, Mike Elsby, Jason Faberman, William Hawkins, Matthias Hertweck, Yang Jiao, Iourii Manovskii, David Ratner, Richard Rogerson, Gianluca Violante, and Ludo Visschers, David Comerford for research assistance, as well as seminar and conference audiences at BI Oslo, Carlos III, Chicago, Chicago Fed, CEMFI, Cologne Macroeconomics Workshop, Columbia University, Deutsche Bundesbank, CREI, EEA (Oslo), Essex Economics and Music, ETH Zurich, Labour Market Search and Policy Applications (Konstanz), Leicester, NBER Summer Institute (Boston), NYU, Philadelphia Fed, Royal Holloway, SAET (Faro), SED (Montreal, Seoul), SITE, St. Gallen, St. Louis Fed, Tor Vergata Rome, Toulouse, UC Los Angeles, UC San Diego, UC Santa Barbara, University of Pennsylvania, Verein fuer Socialpolitik, Vienna Macroeconomics Workshop (Rome) and Yale. Kircher gratefully acknowledges support from the National Science Foundation and the European Research Council.

${ }^{\dagger}$ Department of Economics, University of Konstanz, leo.kaas@uni-konstanz.de

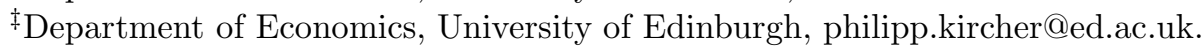




\section{Introduction}

Search models of the labor market following the Diamond-Mortensen-Pissarides framework have traditionally abstracted from the role of firms, concentrating on the concepts of jobs and vacancies (see, e.g., Rogerson et al. (2005)). While a recent wave of contributions include firm size through decreasing returns in production, they rely on the standard assumption that vacancies are filled at a common matching rate which depends on aggregate market conditions but is independent of the characteristics of the firm that posts the job. In this paper we propose an alternative theory in which heterogeneous firms compete for workers through their wage announcements, which naturally implicates differential jobfilling rates across firms. This theory predicts several relations for the crosssection of firms and for the time-variation over the business cycle that seem to match with recent empirical findings. The firm dynamics are efficient, and the model setting remains tractable even in the presence of aggregate shocks.

Recent empirical evidence highlights that the probability of filling jobs depends on the characteristics of the firm. In the cross-section, Davis et al. (2013) show that firms expand faster not only by posting more vacancies, but especially by filling these vacancies at higher rates; for example, the job-filling rate almost doubles as monthly employment growth increases from $10 \%$ to $20 \%$. Across time, they back out an aggregate measure of "recruiting intensity" that moves pro-cyclically, leading to a lower level of matching efficiency for a given labor market tightness in downturns.

Our theory models firms through decreasing returns to labor as in Hopenhayn and Rogerson (1993). In the labor market, we follow the competitive search literature (e.g. Moen (1997)) where employers can publicly post long-term wage contracts to attract unemployed workers. When a firm attracts more workers to its vacancies, the matching rate increases. In our setting with large firms, we allow 
the firms to choose the number of vacancies alongside the posted wage contracts, and it is in fact optimal for them to use both margins. Therefore, matching rates are not an aggregate object but are firm-specific. Growing firms decide to offer better contracts if it is increasingly costly to hire additional workers, which arises, for example, when recruitment takes up time of the existing workers (Shimer (2010)), so that firms expand their workforce slowly over time. We argue that this feature not only generates varying job-filling rates at the micro level, but also gives rise to sensible aggregate dynamics. Particularly, important labor market variables, such as the job-finding rate, react with delay to aggregate shocks. While such sluggish adjustment is consistent with the evidence from vector autoregressions (e.g. Fujita and Ramey (2007)), it is hard to reconcile with the textbook search and matching model (Shimer (2005)). In a quantitative assessment, our model tracks well both the cross-sectional variation as well as the business-cycle variation of recruiting intensity described by Davis et al. (2013). It also leads to slow adjustment of the aggregate job-finding rate and other desirable business-cycle properties.

Our view that firms can attract workers to their vacancies is aimed to capture the features mentioned above and to provide an alternative framework to think about job creation and job destruction of heterogeneous firms in frictional labor markets that contrasts with the prevailing workhorse model based on random search and bilateral bargaining pioneered by Stole and Zwiebel (1996) and Smith (1999). ${ }^{1}$ One obvious difference between the models is the rate at which firms fill their jobs. In the existing contributions, this is governed by the aggregate matching function, so that firms can only hire more if they post more vacancies,

\footnotetext{
${ }^{1}$ Subsequent work adopts this approach to study, for example, unemployment and efficiency (Bertola and Caballero (1994), Acemoglu and Hawkins (2014)), labor and product market regulation (Koeniger and Prat (2007), Ebell and Haefke (2009)), business cycles (e.g., Elsby and Michaels (2013), Fujita and Nakajima (2013)), and international trade and its labor market implications (Helpman and Itskhoki (2010)).
} 
which conflicts with the evidence cited above. Our model naturally focuses on both recruiting margins, the number of vacancies and their filling rate.

A second difference to the prevailing models concerns the normative implications. In the bargaining frameworks, firms hire excessively in order to depress the wages of all their workers, yielding a within-firm externality (see e.g. Smith $(1999)){ }^{2}$ In our setting, contracts are long-term, eliminating the inefficiency within the firm. Combined with public posting of wage contracts this induces efficient outcomes both on the extensive margins of firm entry/exit and on the intensive margins of firm expansion/contraction, governed by a modified Hosios (1990) condition. This extends standard efficiency results of competitive search (see e.g. Moen (1997)) to settings with rich firm dynamics. ${ }^{3}$

Finally, we establish that our environment is particularly tractable, even outside of steady state. While one could possibly add recruiting intensity to existing bargaining models, the complications arising from such settings, especially in the presence of aggregate shocks, make this difficult. Tractability in our model arises from free entry of firms and competitive search. When a firm decides whether to hire and what contracts to offer, it needs to know the workers' utility value of unemployment, as this defines the relevant outside option. This utility value generally depends on the distribution of other firms in the market, which is an infinite-dimensional object. In our setting, since workers can choose where to search for a job, they are indifferent between existing firms and new entrants,

\footnotetext{
${ }^{2}$ In contrast to one-worker bargaining models, the inefficiency cannot be corrected by an appropriate level of the bargaining power parameter. Even with wage commitments, the randomness of the search process generates an across-firm externality that impedes efficiency (see Hawkins (2014)).

${ }^{3}$ We are not aware of a formal efficiency result for large firms operating under decreasing returns. Hawkins (2013) suggests such an outcome on the basis of a static model, but his results are complicated by the stochastic nature of the hiring process and they do not extend to his dynamic setting with shocks. Menzio and Moen (2010) do not obtain efficiency because they focus on lack of commitment, and Garibaldi et al. (2014) abstract from decreasing returns. While efficiency often obtains in competitive-search settings, the subtle nature of search markets does not render this insight obvious when choices along different margins interact (cf. Galenianos and Kircher (2009), Guerrieri (2008), and Footnote 20).
} 
and the latter number adjusts to equate the marginal benefit to the entry costs, independent of the existing firms. This implies that only the current aggregate productivity enters the workers' utility value and hence the firms' optimization problem, eliminating the need for approximation techniques like those of Krusell and Smith (1998) that are usually necessary to study business cycles with heterogeneous firms (e.g. Elsby and Michaels (2013), Fujita and Nakajima (2013)).

The fact that individual firms' policy functions jump with business cycle shocks does not imply, however, that important aggregate variables, such as the workers' job-finding rate, jump as well. To the contrary, the distribution of firms evolves slowly and many job openings are not governed by free entry. Hence, the aggregate job-finding rate and the vacancy-unemployment ratio feature a slow response to business-cycle shocks, as documented by Fujita and Ramey (2007) and Fujita (2011), as well as an imperfect correlation with aggregate productivity (Shimer $(2005))$.

The idea that policy functions are jump variables also features in Pissarides (2000) for random search and in Shi (2009) and Menzio and Shi $(2010,2011)$ for competitive search, but in those settings there is entry at all wage contracts and the job-finding rate is a jump variable, perfectly correlated with aggregate productivity. ${ }^{4}$ Since the link between firm-level dynamics and aggregate dynamics is important, we explore this feature in more detail in the quantitative section of this paper. Indeed we demonstrate that the calibrated model generates aggregate labor market dynamics that are largely in line with the U.S. business cycle. It generates sluggish responses of key labor market variables, and aggregate measures of the vacancy yield and of the recruiting intensity show similar cyclicality and volatility as found by Davis et al. (2013).

\footnotetext{
${ }^{4}$ In Shi (2009) and Menzio and Shi (2010, 2011), firms are indifferent between all contracts and there is free entry at every contract. In our setting, the workers are indifferent between all wage contracts, but there is still free entry on the firms' side. This additional feature brings about the difference in some results, while retaining tractability.
} 
Our work describes the recruitment behavior of firms competing for unemployed workers. One could envision additionally competition for employed workers. Burdett and Mortensen (1998), Postel-Vinay and Robin (2002) and Moscarini and Postel-Vinay (2013) explore this in random search environments, but the complexity of these models makes it difficult to study firm dynamics, as firms are usually assumed to face neither idiosyncratic nor aggregate shocks. ${ }^{5}$ In the competitive-search literature, job-to-job mobility has been considered by Shi (2009), Menzio and Shi (2010, 2011), Garibaldi et al. (2014) and recently Schaal (2012). Except for the last contribution, firm size in these models is not restricted by the operated technology, circumventing considerations induced by the difference between average and marginal product. Schaal (2012) differs from ours by assuming linear recruitment costs, which imply that firms immediately jump to their desired sizes, they are indifferent between all contracts and hence face identical job-filling rates, and there is no aggregate sluggishness.

To build intuition for our model and to highlight its features, we first analyze a simplified environment without productivity shocks. In that setting we derive implications relating firm size and growth to pay and job-filling rates. Subsequently we establish tractability and efficiency in the presence of shocks, and discuss the robustness of our propositions. We then move to a quantitative assessment to analyze the main cross-sectional and business-cycle features. As a policy application, we explore the impact of hiring subsidies on labor market dynamics. All proofs and some extensions are relegated to the Appendix.

\footnotetext{
${ }^{5}$ Moscarini and Postel-Vinay (2013) do allow for aggregate shocks, but their requirement of rank-preserving hiring prevents the study of firm entry and firm-specific shocks. To our knowledge, the only model that explicitly focuses on firm dynamics is Lentz and Mortensen (2012), which combines decreasing returns with on-the-job search, but again it has no idiosyncratic or aggregate shocks.
} 


\section{The Model}

\subsection{The Environment}

The model is set in discrete time and has a continuum of workers and firms. The mass of workers is normalized to one. Each worker is infinitely-lived, riskneutral, and discounts future income with factor $\beta<1$. A worker supplies one unit of labor per period when employed and receives income $b \geq 0$ when unemployed. Only unemployed workers search for employment, so there are no job-to-job transitions. On the other side of the labor market is an endogenous mass of firms. Firms are large relative to workers, in the sense that each active firm employs a continuum of workers. Firms are also risk neutral and have the same discount factor $\beta$.

In each period, a firm produces output $x z F(L)$ with $L \geq 0$ workers, where $F$ is a twice differentiable, strictly increasing and strictly concave function satisfying $F^{\prime}(0)=\infty$ and $F^{\prime}(\infty)=0 . \quad x \in X$ is idiosyncratic productivity and $z \in Z$ is aggregate productivity. Both $x$ and $z$ follow Markov processes on finite state spaces $X$ and $Z$ with respective transition probabilities $\pi\left(x_{+} \mid x\right)$ and $\psi\left(z_{+} \mid z\right)$. Each existing firm pays an operating cost $f \geq 0$ per period. Each new entrant pays setup cost $K(z)$, possibly dependent on the aggregate state, and draws an initial productivity level $x_{0} \in X$ with probability $\pi_{0}\left(x_{0}\right)$. Firms die with exogenous probability $\delta_{0}>0$, in which case all workers are laid off into unemployment. Furthermore, each worker quits a job with exogenous probability $s_{0} \geq 0 . \delta_{0}$ are $s_{0}$ are lower bounds on the actual exit and separation rates $\delta \geq \delta_{0}, s \geq s_{0}$, since firms may decide to leave the market or to lay off some workers in the event of an adverse productivity shock.

Search for new hires is a costly activity. A firm with workforce $L$ and productivity $x z$ that posts $V$ vacancies incurs recruitment costs $C(V, L, x z)$. Apart 
from twice differentiability, we assume that a firm's output net of recruitment costs is strictly increasing in $(L, x z)$ and strictly concave in $(V, L)$. In particular, this requires that $C$ is strictly convex in $V$. Popular functional form are

$$
C(V, L, x z)=x z F(L)-x z F(L-h V)+k(V) \quad \text { or } \quad C(V, L, x z)=\frac{c}{1+\gamma}\left(\frac{V}{L}\right)^{\gamma} V
$$

In the first specification, $k(V)$ captures some convex monetary costs (see e.g. Cooper et al. (2007)) and $h V$ captures labor input in recruitment (see e.g. Shimer (2010)). Even in the absence of monetary costs and despite linearity of the labor input, this leads to convex costs because of decreasing returns in production. ${ }^{6}$ The second, constant-returns specification, which is borrowed from Merz and Yashiv (2007), assumes that average costs per vacancy depend on the vacancy rate (i.e. vacancies divided by employment), allowing larger firms with proportionally higher vacancies to incur the same unit costs. ${ }^{7}$ In either setting, firms cannot instantaneously grow large simply by posting enough vacancies at constant marginal cost. For some proofs of cross-sectional relationships derived below (Proposition 1 and subsequent corollaries), we focus on cost functions such as those in (1) which satisfy the following properties on cross-derivatives: ${ }^{8}$

\footnotetext{
${ }^{6}$ Clearly no more workers can be engaged in hiring than are present at the firm. To get the hiring process started for entrant firms, we need to assume that a new firm is endowed with initial labor input of the entrepreneur $L_{e}$ so that the actual labor input is $\tilde{L}=L_{e}+L$. Recruitment activities are then constrained by $h V \leq L+L_{e}$, and Inada conditions on $F$ ensure that this constraint never binds. A similar adjustment is needed for the second specification in (1) to avoid division by zero at entrant firms (see Section 3).

${ }^{7}$ To be precise, Merz and Yashiv (2007) specify and estimate convex adjustment costs (at the aggregate level) that depend on hires rather than vacancies. Relatedly, Blatter et al. (2012) estimate hiring costs on Swiss firm-level data and also find evidence for convexity. Costs that depend on hires better reflect training costs and could additionally be introduced into our framework. Costs that depend on the number of job openings capture recruiting costs and are more common in the search and matching literature.

${ }^{8}$ The first two conditions state that an additional vacancy is more expensive if the firm is smaller or if it is more productive. This arises in (1) because in a smaller firm a given number of vacancies has a higher weight, while at higher productivity it is more costly to withdraw workers from production. The third condition guarantees that the firm's value function is supermodular in $(x z, L)$ (i.e. more productive firms gain more from being larger), since output
} 


$$
C_{12} \leq 0, C_{13} \geq 0, \text { and }-C_{12} C_{13} / C_{11} \leq F^{\prime}-C_{23} \text {. }
$$

We formulate a competitive search equilibrium in which firms compete for workers by posting long-term contracts. Unemployed workers direct their job search towards the most attractive offers: they can observe all contracts and choose for which one to search. At any type of contract, job seekers and vacancies are matched according to a matching function: if a contract attracts $\lambda$ workers per vacancy, the matching function determines the probability $m$ with which each vacancy gets filled. Therefore, a firm fills its vacancies with probability $m$ only if it offers a contract that attracts $\lambda(m)$ unemployed job seekers per vacancy. ${ }^{9}$ Standard assumptions on the matching function guarantee that this function is twice differentiable, strictly increasing and strictly convex in $m$, with $\lambda(0)=0$, $\lambda^{\prime}(0) \geq 1$ and $\lambda^{\prime}(1)=\infty .{ }^{10}$ It is increasing since firms achieve a higher matching probability only if more workers are searching for their vacancies. It is convex since it becomes increasingly difficult to increase the matching rate when more workers are attracted to the vacant job. The workers' matching probability is $m / \lambda(m)$, which is strictly decreasing.

The labor market within each period operates in three stages. First, aggregate productivity is revealed, new firms enter, and idiosyncratic productivities are revealed. Second, firms produce and they decide about vacancy postings, contracts offered to new hires, layoffs, and possibly about exiting at the end of

minus vacancy costs are supermodular in these variables (right-hand side) and larger than any countervailing indirect effects that these variable have via the number of vacancies (left-hand side). This holds trivially if costs are independent of either productivity or size.

${ }^{9}$ We follow the standard assumption in the search literature with large firms ithat each job has its own matching probability, i.e., applicants from one job cannot be hired at another job in the same firm, which arises, for example, if different jobs require different qualifications. Only few papers explore the idea that workers are literally identical and can be hired for another job than the one they applied for (see Burdett et al. (2001), Hawkins (2013) and Lester (2010)).

${ }^{10}$ Function $\lambda$ is the inverse of the standard matching function $\tilde{m}:[0, \infty) \rightarrow[0,1)$ that maps the realized unemployed-vacancy ratio $\tilde{\lambda}$ into the hiring probability. Typically, $\tilde{m}$ is assumed to be strictly increasing and strictly concave, and $\tilde{m}(\tilde{\lambda}) \leq \min (1, \tilde{\lambda})$ guarantees that $\tilde{m}^{\prime}(0) \leq 1$. Therefore, we can define $\lambda(m)=\tilde{m}^{-1}(m)$, and the properties in the text follow. 
the period. Separated workers enter the unemployment pool and start to search for employment in the next period. And third, unemployed workers and vacant jobs are matched. ${ }^{11}$

In the next section, we consider a stationary environment without idiosyncratic or aggregate productivity shocks. This allows us to focus on firm growth in a particularly tractable labor market model with a simple contract space. We extend this environment in Section 2.3.

\subsection{The Stationary Model}

This section abstracts from productivity shocks. That is, we set aggregate productivity to $z=1$. Idiosyncratic productivity stays constant throughout the life of a firm but may differ across firms who draw their productivity upon entry. We also set operating costs $f$ to zero. The absence of shocks implies in particular that firms neither voluntarily exit the market, nor do they lay off any workers. Hence, the exit and separation rates are exogenous, $\delta=\delta_{0}$ and $s=s_{0}$, and so is any worker's retention probability $\varphi \equiv(1-\delta)(1-s)$.

To attract unemployed job seekers, a recruiting firm announces a flat flow wage $w$ to be paid to its new hires for the duration of the employment relation. The assumption that the firm offers the same wage to all its new hires turns out not to entail a restriction; see the discussion following equation (5) below. Further, because of risk neutrality, only the net present value that a firm promises to the worker matters. Flat wages are one way of delivering these promises. ${ }^{12}$

Unemployed workers direct their search optimally to the wages offered by firms. To understand what wage $w(m)$ a firm has to offer in order to achieve matching

\footnotetext{
${ }^{11}$ It follows from this specification that new entrants can only produce output with their first hires in the period after entry.

${ }^{12}$ This is a theory of the present value of offered wages. Constant wages can be viewed as the limiting case of risk-neutral firms and risk-averse workers, as risk aversion vanishes. But other payment patterns are conceivable; for further discussion about this issue, see Section 2.3.2.
} 
probability $m$, note that in a stationary environment an unemployed worker who is seeking for a particular wage in one period is willing to search for that wage in every period. ${ }^{13}$ Let $U$ denote the discounted present value from such job search. It is given by the following asset value equation: ${ }^{14}$

$$
(1-\beta) U=b+\underbrace{\frac{m}{\lambda(m)} \beta(1-\delta) \frac{w(m)-(1-\beta) U}{1-\beta \varphi}}_{\equiv \rho} .
$$

It states that the flow value of unemployment equals the current period unemployment income $b$ together with an option value from searching, denoted by $\rho$. The search value is the probability of finding a job multiplied with the worker's discounted job surplus. Since workers have a choice where to search for a job, their flow value from unemployment must be equal in all markets that attract workers. Therefore, $\rho$ is a global value that is common to all markets, which means that a firm has to offer the following wage to achieve matching rate $m>0$ :

$$
w(m) \equiv b+\rho+\frac{1-\beta \varphi}{\beta(1-\delta)} \frac{\lambda(m)}{m} \rho .
$$

This relation says that a firm can only recruit workers when its wage offer matches the workers' unemployment value $(1-\beta) U=b+\rho$ plus a premium which is needed to attract workers to jobs with filling rate $m$. This premium is increasing in $m$, which is a crucial insight. The relationship between job-filling rates and wage offers is standard in the competitive search literature.

\footnotetext{
${ }^{13}$ Note that unemployed workers are indifferent between all equilibrium search strategies. Hence this model makes no predictions about the relationship between wages and unemployment duration.

${ }^{14}$ Bellman equations for employed and unemployed workers are $E=w+\beta[\varphi E+(1-\varphi) U]$ and $U=b+\beta\left[m \lambda(m)^{-1}(1-\delta) E+\left(1-m \lambda(m)^{-1}(1-\delta)\right) U\right]$. Equation (2) follows by substituting the first into the second.
} 


\subsubsection{The Firms' Recruitment Policies}

Consider the problem of a firm that takes the search value of unemployed workers and the associated relationship (3) as given. Later, the search value will be determined as an equilibrium object that depends on the number of firms and their wage offers.

Let $J^{x}(L, W)$ be the value function of a firm that has productivity $x$, employs $L$ workers and is committed to a wage bill of $W$ per period for its current workforce. Wages are commitments that have to be fulfilled as long as a worker does not separate. Therefore, the firm has to pay a net present value of existing commitments of $W /(1-\beta \varphi)$ independent of its future hiring decisions, which implies $J^{x}(L, W)=J^{x}(L, 0)-W /(1-\beta \varphi)$. This allows us to focus on $J^{x}(L, 0)$, which eliminates the wage bill as a state variable. The firm's recruitment choices involve the number of posted vacancies $V$ as well as the job-filling probability $m$, which requires a wage offer of $w(m)$. Its recursive profit maximization problem is expressed as

$$
\begin{aligned}
J^{x}(L, 0)= & \max _{(m, V) \in[0,1] \times \mathbb{R}_{+}} x F(L)-C(V, L, x)-D(m) V+\beta(1-\delta) J^{x}\left(L_{+}, 0\right) \\
& \text { s.t. } L_{+}=L(1-s)+m V
\end{aligned}
$$

where $D(m) V \equiv w(m) \beta(1-\delta) /(1-\beta \varphi) m V$ represents the net present value of the additional wage commitments for its $m V$ new hires, whose wages are paid once they enter production next period. The other terms in the first line represent output, recruitment costs, and the value of continuing with a changed workforce. The second line says that employment next period consists of the retained workers and the new hires.

Problem (4) makes it readily apparent that a firm has two channels to hire workers in a given period. It can increase the number of vacancies and associated 
$\operatorname{costs} C$, or it can increase the filling rate of each job and associated costs $D$. Note that both $C(\cdot, L, x)$ and $D(\cdot)$ are convex - the latter inherits this from matching function $\lambda(m)$. This implies that firms use both recruitment channels if they want to hire faster: more vacancies and higher matching rates per vacancy. This can readily be seen from the optimality conditions for the control variables in (4). These are derived rigorously in Appendix A, but we provide some intuition here for the main trade-offs. The optimal choices for the number of vacancies and their matching probability are governed by one intratemporal and one intertemporal optimality condition.

Regarding the intratemporal optimality condition, consider a firm that aims to hire $H$ workers in this period. It faces the problem of choosing the number of vacancies and the job-filling probability to minimize costs $C(V,)+.D(m) V$ subject to $H=m V$. The first-order condition for this problem is

$$
C_{1}(V, L, x)=D^{\prime}(m) m-D(m)=\rho\left[m \lambda^{\prime}(m)-\lambda(m)\right]
$$

This links the marginal recruitment costs to the marginal increase in wage costs associated with increases in the job-filling probability.

Relationship (5) offers a number of insights. It defines the optimal policy for vacancy postings $V=V^{x}(m, L)$ as a function of the job-filling rate and firm size. Because of convex recruitment costs, this policy function is increasing in $m$; thus, vacancy postings and job-filling rates are complementary tools in the firm's recruitment strategy. This captures the basic stylized fact highlighted by Davis et al. (2013) that firms use both more vacancies as well as higher job-filling rates to achieve faster growth. ${ }^{15}$ In contrast, under constant marginal recruitment costs $\left(C_{1}(V, L, x)=c\right)$, as assumed in much of the literature, the job-filling rate

\footnotetext{
${ }^{15}$ The first equation in (5) suggests that this argument holds in a broader class of models in which firms can influence job-filling rates. In our model, job-filling rates are increased via higher wage offers which reflects the allocative role of wages in the labor market.
} 
would be constant and independent of firm characteristics, while all employment adjustment is instantaneous and is achieved through the number of vacancies. Finally, note that equation (5) balances the wage costs for new hires against recruitment costs at a unique point, which shows why a firm would not want to offer different wages at a given point in time even if this were permissable.

The firm also decides how to structure hiring over time. This is governed by an intertemporal optimality condition which reads

$$
x F^{\prime}\left(L_{+}\right)-C_{2}\left(V_{+}, L_{+}, x\right)-b-\rho=\frac{\rho}{\beta(1-\delta)}\left[\lambda^{\prime}(m)-\beta \varphi \lambda^{\prime}\left(m_{+}\right)\right] .
$$

Here $L_{+}, V_{+}$, and $m_{+}$are employment, vacancy postings and the job-filling rate in the next period. The left-hand side of (6) gives the marginal benefit of a higher workforce in the next period. If this is high, then the firm rather hires more now than to wait and hire next period, as expressed by the right-hand side which is increasing in the current job-filling rate $m$ and decreasing in $m_{+}$. In particular, a more productive firm wants to achieve fast growth by offering a more attractive contract now rather than later, thus raising the current job-filling rate. Equation (6) implicitly defines the optimal job-filling policy $m^{x}(L)$. Starting from $L=0$, this determines the firm's growth path through $L_{+}=L(1-s)+m^{x}(L) V$, where $V=V^{x}\left(m^{x}(L), L\right)$ comes from the static optimality condition (5).

An illustration how a firm grows over time is provided in Figure 1 which shows the phase diagram in $(L, m)$ space for the firm's problem with recruitment costs $C(V, L, x)=x F(L)-x F(L-h V)+c V$ for which the optimality conditions become especially tractable. ${ }^{16}$ Initially the firm is small and the optimal job-filling rate

\footnotetext{
${ }^{16}$ In Lemma A.3 of the Appendix we show that equations (5) and (6) simplify to only one equation linking $m_{t}$ and $m_{t+1}$, which is independent of $L_{t}$. This equation has a unique long-run job-filling probability $m^{*}>0$ if $h$ is low enough, and $m_{t}$ converges to $m^{*}$ from any initial value $m_{0}>0$. Employment adjusts according to $L_{t+1}=L_{t}(1-s)+m_{t} V^{x}\left(m_{t}, L_{t}\right)$. Using (5), it is easy to see that the curve $L_{t+1}=L_{t}$ is downward-sloping in $(L, m)$ space, so that the saddle path lies above this curve when $L_{t}<L^{*}$.
} 
exceeds the long-run rate $m^{*}$. This rate is the firm's policy after it converges to its long-run optimal size $L^{*}>0$ where it only conducts replacement hiring. The downward-sloping saddle path depicts the firm's policy function $m^{x}(L)$ and describes the adjustment process to the long-run optimal size, along which the firm spreads recruitment costs over time. This is in contrast to a model with linear recruitment costs in which firms would jump directly to $\left(L^{*}, m^{*}\right)$. In terms of comparative statics, this example also shows that the stationary firm size and the job-filling rates along the transition depend positively on $x$ : a more productive firm grows larger and offers higher lifetime wages on its transition to the long-run employment level. The following proposition and its corollaries provide broader

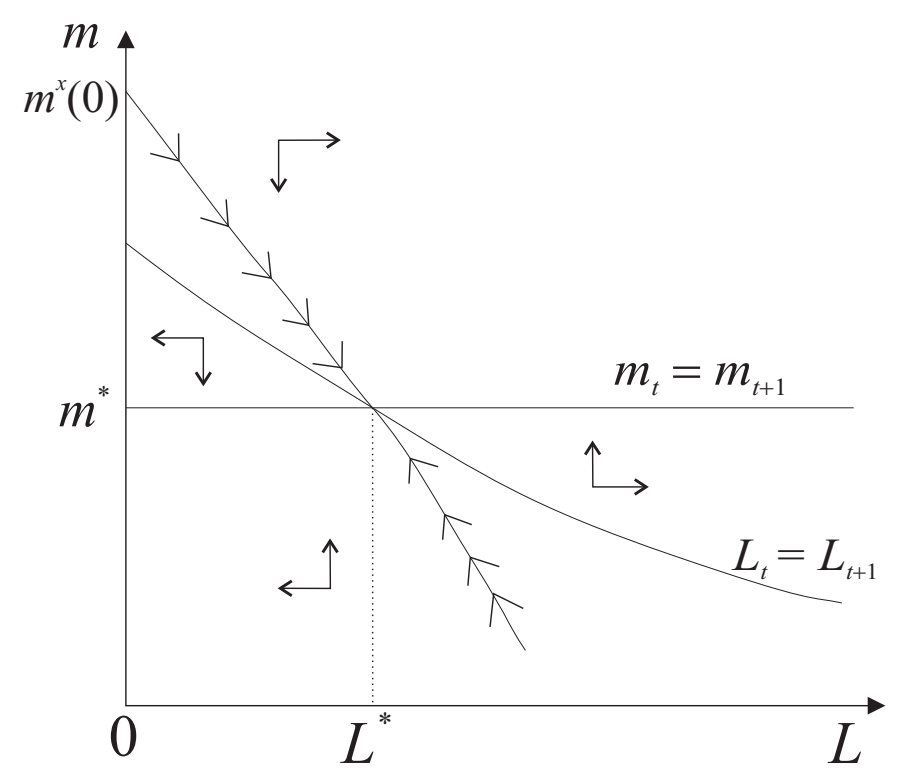

Figure 1: The firm's optimal recruitment policy follows the declining saddle path.

comparative statics results. The job-filling rate is linked via (3) to the wage offer, so that the findings carry over to the net present value of wages to new hires. ${ }^{17}$

\footnotetext{
${ }^{17}$ These characterization results depend crucially on the supermodularity of the value function, which renders this proof non-trivial. While standard techniques (Amir (1996)) can be applied when the cost function is independent of firm size and productivity, this is not true in general, as we discuss in Appendix A.
} 
Proposition 1: Consider recruitment cost functions satisfying property $(C)$. The firm's value function $J^{x}(L, W)$ is strictly increasing and strictly concave in its workforce $L$, strictly increasing in productivity $x$, strictly supermodular in $(x, L)$ and decreasing in the worker's search value $\rho$. The job-filling rate $m^{x}(L)$ is strictly increasing in productivity $x$ and strictly decreasing in the workforce L. Posted vacancies $V^{x}(m, L)$ are increasing in $L$ and strictly increasing in the desired job-filling rate $m$.

Since these results hold for any search value $\rho$, they also apply when this value is determined in general equilibrium. These results imply relationships between size, productivity, pay, and hiring:

Corollary 1: Consider recruitment cost functions satisfying property $(C)$. Conditional on size, more productive firms pay higher lifetime wages and have a higher job-filling rate. Conditional on productivity, younger/smaller firms pay higher lifetime wages and have a higher job-filling rate.

In Appendix A we also prove the following connection to firm growth rates.

Corollary 2: If recruitment costs are given by either specification in (1) with parameter h sufficiently small, more productive firms have a higher growth rate, conditional on size; and larger/older firms have a lower growth rate, conditional on productivity.

While it already follows from (5) that vacancy postings and job-filling rates are positively related, the two corollaries link these policies to the firm's growth rate. They point out that job-filling rates and firm growth rates are positively correlated, depending positively on $x$ and negatively on $L$. This cross-sectional relationship has been highlighted recently by Davis et al. (2013), and we further explore in Section 3 how well our model captures this quantitatively. Furthermore, since higher job-filling rates are directly associated with higher earnings for new hires, the two corollaries also imply that faster-growing firms offer higher lifetime wages. Belzil (2000) documents such patterns after controlling for size and 
worker characteristics; he shows that wages, particularly those of new hires, are positively related to a firm's job creation. Our findings that younger firms grow faster (conditional on survival) and pay higher wages (to workers with the same characteristics) are consistent with the evidence (see Haltiwanger et al. (2013), Brown and Medoff (2003) and Schmieder (2013)). Moreover, a positive wage-size relation emerges in our model if the dispersion in productivity is large enough. ${ }^{18}$

\subsubsection{General Equilibrium and Efficiency}

Free entry of firms implies that no entrant makes a positive profit, that is,

$$
\sum_{x \in X} \pi(x) J^{x}(0,0) \leq K
$$

with equality if entry is positive. This condition implicitly pins down the workers' job surplus $\rho$ and therefore the relationship between wages and job-filling rates. In a stationary equilibrium, a constant mass of $N_{0}$ firms enter the market in every period, so that there are $N_{a}=N_{0}(1-\delta)^{a}$ firms of age $a$ in any period. Let $\left(L_{a}^{x}, m_{a}^{x}, V_{a}^{x}, w_{a}^{x}\right)_{a \geq 0}$ be the employment/recruitment path for a firm with productivity $x$. Then, a firm of age $a$ has $L_{a}^{x}$ employed workers, and $\lambda\left(m_{a}^{x}\right) V_{a}^{x}$ unemployed workers are searching for jobs with offered wage $w_{a}^{x}$. Therefore, the mass of entrant firms $N_{0}$ is uniquely pinned down from aggregate resource feasibility:

$$
1=\sum_{a \geq 0} N_{0}(1-\delta)^{a} \sum_{x \in X} \pi(x)\left[L_{a}^{x}+\lambda\left(m_{a}^{x}\right) V_{a}^{x}\right]
$$

This equation says that the unit mass of workers is either employed or unemployed. We now define a stationary equilibrium.

\footnotetext{
${ }^{18}$ We note that enough productivity dispersion is also required in models with intra-firm bargaining, and even more so because wages of all workers decline in a growing firm.
} 
Definition: A stationary competitive search equilibrium is a list $\left(\rho, N_{0},\left(L_{a}^{x}, m_{a}^{x}, V_{a}^{x}, w_{a}^{x}\right)_{x \in X, a \geq 0}\right)$ with the following properties. Unemployed workers' job search strategies maximize utility: (3) holds for all $\left(w_{a}^{x}, m_{a}^{x}\right)$. Firms' recruitment policies are optimal: $\left(L_{a}^{x}, m_{a}^{x}, V_{a}^{x}\right)_{a \geq 0}$ solve (4) for all $x \in X$. There is free entry of firms: (7) and $N_{0} \geq 0$ hold with complementary slackness. Aggregate resource feasibility (8) holds.

Since the firms' behavior has already been characterized, it remains to explore equilibrium existence and uniqueness.

Proposition 2: A stationary competitive search equilibrium exists and is unique. There is strictly positive firm entry provided that $K$ is sufficiently small.

The previous section already outlined that this model generates sensible relationships between productivity, size, growth, and job-filling rates. It is relevant to understand whether these patterns are actually socially efficient, especially since existing models with intra-firm bargaining always entail inefficiencies, as discussed in the introduction. Indeed we establish in the next section that a competitive search equilibrium is socially efficient. ${ }^{19}$ A planner who decides at each point in time about entry, vacancy postings and job filling rates for all firms would choose exactly the same solution.

The efficiency of equilibrium can be linked to a variant of the well-known Hosios (1990) condition. ${ }^{20}$ It says that efficient job creation requires that the firm's surplus share for the marginal vacancy is related to the elasticity of the

\footnotetext{
${ }^{19}$ See also Proposition A.1 in Appendix A for a direct efficiency result for the stationary equilibrium characterized above.

${ }^{20}$ See also the Hosios condition in a large-firm model with intra-firm bargaining in Hawkins (2014). While an appropriate version of this condition is satisfied in many competitive search models, it can fail in the presence of intensive decision margins despite wage commitments; cf. Galenianos and Kircher (2009) and Guerrieri (2008). Their efficiency failures seem to be driven by intensive margins on the workers' side (search behavior or work effort), which are not internalized by the wage contracts. In our model, extensive and intensive decision margins are on the firms' side and are fully internalized. This point is reminiscent of efficient capacity decisions by firms in static directed search models (cf. Geromichalos (2012) and Godenhielm and Kultti (2014)).
} 
matching function. Write the workers' search value $\rho=\frac{m}{\lambda(m)} S^{w}$ as the product between the match probability and the worker's job surplus $S^{w}$. Then, equation (5) can be rewritten as

$$
C_{1}(V, L, x)=\frac{1-\varepsilon_{m, \lambda}}{\varepsilon_{m, \lambda}} m S^{w}
$$

where $\varepsilon_{m, \lambda}=\frac{\lambda(m)}{\lambda^{\prime}(m) m} \in[0,1]$ is the matching-function elasticity.

\subsection{Productivity Shocks and Firm Dynamics}

In this section we consider much richer dynamics and show that tractability is retained. In the presence of firm-specific and aggregate productivity shocks we cannot only explore the two margins of job creation (firm entry and firm growth), but also the two margins of job destruction (firm exit and firm contraction). A non-trivial endogenous exit margin arises only if operating costs $f$ are strictly positive; otherwise low-productivity firms rather continue with zero workers than to exit.

The incorporation of productivity shocks allows us to study in Section 3 to which extent the model can quantitatively account for the micro-level heterogeneity in the firms' recruitment behavior and how it performs over the business cycle. In light of the aforementioned efficiency result and to simplify the exposition, we start to describe and characterize the planning problem before we show its equivalence to a competitive search equilibrium.

\subsubsection{The Planning Problem}

The planner decides at each point in time about firm entry and exit, layoffs and hires (i.e. vacancy postings and matching probabilities) for all firm types, knowing that matching probability $m$ requires $\lambda(m)$ unemployed workers per 
vacancy. For a firm of age $a \geq 0$, let $x^{a}=\left(x_{0}, \ldots, x_{a}\right) \in X^{a+1}$ denote the history of idiosyncratic productivity, and let $z^{t}=\left(z_{0}, \ldots, z_{t}\right) \in Z^{t+1}$ be the history of aggregate states at time $t$ with corresponding probability $\psi\left(z^{t}\right)$. In a given aggregate history $z^{t}$, we denote by $N\left(x^{a}, z^{t}\right)$ the mass of firms of age $a$ with idiosyncratic history $x^{a} . L\left(x^{a}, z^{t}\right)$ is the employment stock of any of these firms. At every history node $z^{t}$ and for every firm type $x^{a}$, the planner decides an exit probability $\delta\left(x^{a}, z^{t}\right) \geq \delta_{0}$, a separation rate $s\left(x^{a}, z^{t}\right) \geq s_{0}$, vacancy postings $V\left(x^{a}, z^{t}\right) \geq 0$, and a matching probability $m\left(x^{a}, z^{t}\right) .{ }^{21}$ The numbers of firm types change between periods $t$ and $t+1$ according to the Markov chains for the productivities and the planner's exit decision:

$$
N\left(x^{a+1}, z^{t+1}\right)=\left[1-\delta\left(x^{a}, z^{t}\right)\right] \pi\left(x_{a+1} \mid x_{a}\right) \psi\left(z_{t+1} \mid z_{t}\right) N\left(x^{a}, z^{t}\right)
$$

and the workforce at any of these firms adjusts according to the planner's separation and hiring decisions:

$$
L\left(x^{a+1}, z^{t+1}\right)=\left[1-s\left(x^{a}, z^{t}\right)\right] L\left(x^{a}, z^{t}\right)+m\left(x^{a}, z^{t}\right) V\left(x^{a}, z^{t}\right) .
$$

At time $t=0$, the planner takes as given the numbers of firms that entered the economy in some earlier period, as well as the employment stock of each of these firms. Hence, the state vector at date 0 is summarized by the initial firm distribution $\left(N\left(x^{a}, z^{0}\right), L\left(x^{a}, z^{0}\right)\right)_{a \geq 1, x^{a} \in X^{a+1}}$. In a given history $z^{t}$, the planner also decides the mass of new entrants $N_{0}\left(z^{t}\right) \geq 0$, so that

$$
N\left(x_{0}, z^{t}\right)=\pi_{0}\left(x_{0}\right) N_{0}\left(z^{t}\right) \text { and } L\left(x_{0}, z^{t}\right)=0 .
$$

\footnotetext{
21 To save on notation, we do not allow the planner to discriminate between workers with different firm tenure. Given that there is no learning-on-the-job, there is clearly no reason for the planner to do so. Nonetheless, the competitive search equilibrium considered in Section 2.3.2 allows firms to treat workers in different cohorts differently, which is necessary because firms offer contracts sequentially and are committed to these contracts. See the proof of Proposition 4 for further elaboration of this issue.
} 
The sequential planning problem is to maximize the expected discounted output net of entry costs, opportunity costs of work, and operating and recruitment costs:

$$
\begin{gathered}
\max _{\delta, s, V, m, N_{0}} \sum_{t \geq 0, z^{t}} \beta^{t} \psi\left(z^{t}\right)\left\{-K\left(z_{t}\right) N_{0}\left(z^{t}\right)+\sum_{a \geq 0, x^{a}} N\left(x^{a}, z^{t}\right)\left[x_{a} z_{t} F\left(L\left(x^{a}, z^{t}\right)\right)\right.\right. \\
\left.\left.-b L\left(x^{a}, z^{t}\right)-f-C\left(V\left(x^{a}, z^{t}\right), L\left(x^{a}, z^{t}\right), x_{a} z_{t}\right)\right]\right\}
\end{gathered}
$$

subject to the dynamic equations for $N$ and $L$, namely (9), (10) and (11), and subject to the resource constraints, for all $z^{t} \in Z^{t+1}$,

$$
\sum_{a \geq 0, x^{a}} N\left(x^{a}, z^{t}\right)\left[L\left(x^{a}, z^{t}\right)+\lambda\left(m\left(x^{a}, z^{t}\right)\right) V\left(x^{a}, z^{t}\right)\right] \leq 1 .
$$

This constraint says that the labor force (employment plus unemployment) cannot exceed the given unit mass of workers. We summarize a solution to the planning problem by a vector $(\mathbf{N}, \mathbf{L}, \mathbf{V}, \mathbf{m}, \mathbf{s}, \boldsymbol{\delta})$, with $\mathbf{N}=\left(N\left(x^{a}, z^{t}\right)\right)_{a, t \geq 0}$ and similar notation for the other variables.

We show that there is a convenient characterization of a planning solution which says that hiring, layoff and exit decisions follow a recursive equation at the level of the individual firm. Specifically, for any existing firm, the planner maximizes the social value of the firm, taking into account the social value of each worker tied to the firm. This social worker value is given by the multiplier on the resource constraint (13) which we denote by $\mu\left(z^{t}\right)$ and which generally depends on the initial firm distribution and on the full state history $z^{t}$.

A particularly powerful characterization can be obtained under the provision that firm entry is positive in all states of the planning solution. When this is the case, the social values of a worker (and thus firm-level value and policy functions) depend only on the current aggregate state but are independent of the 
state history and of the firm distribution.

To gain intuition for this finding, envision any period in which the planner can assign unemployed workers either to existing firms or to new firms. If there are many existing firms, there are fewer workers left to be assigned to new firms. Nevertheless, the social value of any worker that is assigned to a new firm does not change: Each new firm has an optimal hiring policy, and if less workers are assigned to new firms, then proportionally less new firms will be created, leaving the marginal value of each worker unchanged. Therefore, efficient hiring by existing firms requires their marginal social benefit of hiring to be equal to the social benefit at the new firms which depends on the aggregate state alone.

To see the independence of value functions from the firm distribution formally, suppose there are $n$ aggregate states $z \in Z=\left\{z_{1}, \ldots, z_{n}\right\}$, and let $\mu_{i}$ be the social value of a worker in state $z_{i}$. Write $M=\left(\mu_{1}, \ldots, \mu_{n}\right)$ for the vector of social values. Let $G(L, x, i ; M)$ be the social value of a firm with employment stock $L$, idiosyncratic productivity $x$ and aggregate productivity $z_{i}$, satisfying the Bellman equations

$$
\begin{array}{rl}
G(L, x, i ; M)=\max _{\delta, s, V, m} & x z_{i} F(L)-b L-f-\mu_{i}[L+\lambda(m) V]-C\left(V, L, x z_{i}\right) \\
& +\beta(1-\delta) \mathrm{E}_{x, i} G\left(L_{+}, x_{+}, i_{+} ; M\right),
\end{array}
$$

where maximization is subject to $L_{+}=(1-s) L+m V, \delta \in\left[\delta_{0}, 1\right], s \in\left[s_{0}, 1\right], m \in$ $[0,1]$ and $V \geq 0$. The interpretation of this problem is rather straightforward. A firm's social value encompasses flow output net of the opportunity cost of employment, net of fixed costs and recruitment costs, and net of the social cost of workers tied to the firm in this period; these workers include the current workforce $L$ and also $\lambda(m) V$ unemployed workers who are searching for jobs at this firm.

Positive entry in all aggregate states requires that the expected social value of 
a new firm is equal to the entry cost,

$$
\sum_{x \in X} \pi_{0}(x) G(0, x, i ; M)=K\left(z_{i}\right)
$$

This characterization of planning solutions by $(G, M)$ is particularly helpful for numerical applications. Despite considerable firm heterogeneity, the model can be solved by a recursive problem on a low-dimensional state space (14) and the (simultaneous) solution of a finite-dimensional fixed-point problem (15). Importantly, the distribution of firms is irrelevant for this computation. After the corresponding policy functions have been calculated, firm entry follows as a residual of the economy's resource constraint and does depend on the distribution of existing firms: in every period with aggregate state $i$, each existing firm with productivity $x$ and size $L$ attracts $V(L, x, i) \lambda(m(L, x, i))$ job seekers according to the policy functions, while a number $N_{0}\left(z^{t}\right)$ of new firms enter to absorb the remaining job seekers. Since job-finding prospects differ between firms, the aggregate job-finding rate therefore also depends on the firm distribution, as does the evolution of aggregate employment, output and job flows. As we see in the next section, these aggregate variables in fact adjust with delay to aggregate shocks. Because of the dependence of $N_{0}$ on the distribution of employment among existing firms, it cannot generally be guaranteed that the planning solution has positive entry in all state histories. Therefore, this property can only be checked ex-post in simulations of the model. Analytically, we prove that any solution of (14)-(15) which gives rise to positive entry in all state histories describes indeed a solution to the planner's problem. We also find that a unique solution of these equations exists for small aggregate shocks:

\section{Proposition 3:}

(a) Suppose that a solution of (14) and (15) exists with associated allocation $\mathbf{A}=(\mathbf{N}, \mathbf{L}, \mathbf{V}, \mathbf{m}, \mathbf{s}, \boldsymbol{\delta})$ satisfying $N\left(z^{t}\right)>0$ for all $z^{t}$. Then $\mathbf{A}$ is a solution 
of the sequential planning problem (12).

(b) If $K(z), f$, and $b$ are sufficiently small and if $z_{1}=\ldots=z_{n}=\bar{z}$, equations (14) and (15) have a unique solution $(G, M)$. Moreover, if the transition matrix $\psi\left(z_{j} \mid z_{i}\right)$ is strictly diagonally dominant and if $\left|z_{i}-\bar{z}\right|$ is sufficiently small for all $i$, equations (14) and (15) have a unique solution.

This reduction of the planning problem permits a straightforward characterization of the optimal layoff and hiring policies. For a growing firm, it follows from the first-order conditions for $m$ and $V$, similar to equation (5), that

$$
C_{1}\left(V, L, x z_{i}\right)=\mu_{i}\left[m \lambda^{\prime}(m)-\lambda(m)\right]
$$

As in the previous section, this equation implies an increasing relation between matching probabilities and the number of posted vacancies at the firm. With higher $m$, the planner is willing to post more vacancies at higher marginal recruiting cost. Denote the solution to equation (16) by $V=V(m, L, x, i)$, which is positive for $m>\underline{m}(L, x, i)$. The planner's optimal choice of $m$ for firm $(L, x)$ in aggregate state $i$ satisfies ${ }^{22}$

$$
\beta\left(1-\delta_{0}\right) \mathrm{E}_{x, i} \frac{d G}{d L}\left(L_{+}, x_{+}, i_{+} ; M\right)=\mu_{i} \lambda^{\prime}(m)
$$

with $L_{+}=L\left(1-s_{0}\right)+m V(m, L, x, i)$. Therefore, the firm hires if and only if

$$
\beta\left(1-\delta_{0}\right) \mathrm{E}_{x, i} \frac{d G}{d L}\left(L\left(1-s_{0}\right), x_{+}, i_{+} ; M\right)>\mu_{i} \lambda^{\prime}(\underline{m}(L, x, i))
$$

Conversely, the planner wants the firm to lay off workers if

$$
\mathrm{E}_{x, i} \frac{d G}{d L}\left(L\left(1-s_{0}\right), x_{+}, i_{+} ; M\right)<0 .
$$

\footnotetext{
${ }^{22}$ Note that $\delta=\delta_{0}$ and $s=s_{0}$ if the firm hires workers.
} 
The two conditions (17) and (18) show how the firm's policy depends on its characteristics. Small and productive firms recruit workers and grow, whereas large and unproductive firms dismiss workers and shrink. There is also an open set of characteristics where firms do not adjust their workforce (cf. Bentolila and Bertola (1990) and Elsby and Michaels (2013)).

\subsubsection{Decentralization}

We now show that a competitive search equilibrium gives rise to the same allocation as the planning solution. Consider firms that offer workers a sequence of state-contingent wages, to be paid for the duration of the match. They also commit to cohort-specific and state-contingent retention probabilities. Contracts are contingent on the idiosyncratic productivity history of the firm at age $k, x^{k}$, and on the aggregate state history $z^{t}$ at time $t$. Formally, a contract offered by a firm of age $a$ at time $T$ takes the form

$$
\mathcal{C}_{a}=\left(w_{a}\left(x^{k}, z^{t}\right), \varphi_{a}\left(x^{k}, z^{t}\right)\right)_{k>a, t=T+k-a},
$$

where $w_{a}\left(x^{k}, z^{t}\right)$ is the wage paid to the worker in history $\left(x^{k}, z^{t}\right)$, conditional on the worker being still employed by the firm in that instant. $\varphi_{a}\left(x^{k}, z^{t}\right)$, for $k>a$, is the probability of retaining the worker at the end of the period, so $1-\varphi_{a}\left(x^{k}, z^{t}\right)$ is the separation probability.

In Appendix B, we describe the workers' and the firms' search problems and we define a competitive search equilibrium, analogously to the stationary model. We also prove the following welfare theorem.

Proposition 4: A competitive search equilibrium is socially optimal.

It is not hard to see that a wage commitment is sufficient for a firm to implement its desired policy, even if it cannot commit to retention rates. Given risk neutrality, the firm can set the wages following any future history exactly 
equal to the reservation wage (i.e. the flow value of unemployment) which is the sum of unemployment income and the worker's shadow value, $b+\mu\left(z^{t}\right)$. It can achieve any initial transfer to attract workers through a hiring bonus. In this decentralization, the costs of an existing worker are always equal to his social value in the alternative: unemployment and search for another job. Since the flow surplus for any retained worker equals his shadow value, the firm's problem in this case coincides with the planner's problem, so that firing and exiting will be exactly up to the socially optimal level even though the firm does not commit to retention rates. Workers do not have any incentive to quit the job unilaterally, either, because they are exactly compensated for their social shadow value from searching. If the workers also cannot commit to stay, this is the unique wage policy that overcomes the commitment problem on both sides of the market and implements the socially efficient outcome. Alternatively, even a slight degree of risk aversion on the workers' side would give rise to flat wage profiles to offer insurance (cf. Rudanko (2011)). This clarifies that the current model determines surplus sharing only, whereas the time path of payments depends on additional details, like the ability to commit to specific actions (see Schaal (2012) for a related point).

\subsection{Extensions}

This framework delivers propositions for the cross-section and for the business cycle under a rich structure of heterogeneity on the side of firms. It abstracts from a similar richness on the side of the workers, and this section discusses two particular concerns: worker heterogeneity and on-the-job search. Both might be important to capture realistic wage distributions that may be understated in our setup. They might also affect the costs and benefits of posting vacancies, since higher wages can attract not only more but also better workers and can induce 
them to stay longer. While such extensions go beyond the scope of this analysis, the following sketches how they could be integrated into this framework. We also clarify that efficiency is not crucial for our tractability results.

Heterogeneity in worker types requires three adjustments to our setup: production functions that accommodate worker heterogeneity; recruitment costs that may be type-dependent; and contract offers that condition on worker type. ${ }^{23} \mathrm{We}$ expect an analogue of our steady-state result when costs are type-dependent: More workers of a particular type can be hired via more vacancies for this type or via higher wages which attract more of these workers, and curvature in the cost function implies that firms will use both margins. Aggregation across types requires further investigation, but technically we expect no particular difficulties.

With aggregate shocks a major technical simplification of our setup is arises since the value of an unemployed worker tracks the current state of aggregate productivity, independent of the distribution of employment across firms. This is driven by entrant firms which absorb workers. With worker heterogeneity, a similar simplification can be expected if there is a separate firm entry margin for each worker type, for example, if firms decide ex-ante which worker type to hire (at least in the first period of the firm's existence). Alternatively, consider a setting where firms choose their level of productivity $x$ at entry cost $K(x)$ and operate a production technology as in Eeckhout and Kircher (2012) where different firm types have a comparative advantage in specializing in different worker types. We conjecture that specialized entry for each worker type will render the business cycle tractable. ${ }^{24}$

Another extension is to add on-the-job search to our basic setup, similar to

\footnotetext{
${ }^{23}$ If contracts cannot condition on worker types, either because of contractual incompleteness or imperfect information at the hiring stage, we enter a world of adverse selection which requires a different approach; see Guerrieri et al. (2010).

${ }^{24}$ If $x$ can be drawn from a continuum, for example, we expect that each worker productivity level will induce a particular firm type to enter, by a logic similar to that in the one-workerper-firm model of Shi (2001).
} 
Schaal (2012) and Garibaldi et al. (2014). As discussed in the introduction, the former assumes linear vacancy costs, which implies that firms always jump to their optimal sizes. The latter assume linear output in combination with convex costs and focus on steady states: Firms grow each period by exactly the same amount and never cease to grow until they exit exogenously. Neither paper considers convex recruitment costs and business cycles. When firms can hire unemployed or employed workers, this is akin to worker heterogeneity, and, as described above, an entry margin for each level of heterogeneity is important for tractability. We conjecture that entrants' choice of productivity $x$ at cost $K(x)$ would give rise to such a specialized entry. ${ }^{25}$

Finally, we note that efficiency is not crucial for tractability. Tractability arises when workers can choose to apply to new firms and there is entry of such firms. The former implies that the utility value of an unemployed worker is linked to new entrants, and the latter ties this to the entry costs. These remain present, e.g., when workers are risk averse. In this case our analysis gives the benchmark of perfect insurance markets. In the absence of private or public insurance, workers search too much for low-paying but easy-to-get jobs (as in Acemoglu and Shimer (1999)), leading to excess employment in low-productivity firms and therefore to a misallocation of labor among heterogeneous firms. This can be studied in a tractable manner in an adaptation of our framework.

\footnotetext{
${ }^{25}$ Employed workers are similar to unemployed workers, except that their existing job provides them with a better outside option. Therefore, when comparing job-finding probabilities and wages, they value the latter more. On the firm side, high-productivity firms care more about hiring probabilities than about wages. This suggests that high-productivity firms specialize on workers whose current level of pay is high. The exact details depend on whether contracts can condition on the worker's search behavior. Our general contract space allows for back-loaded wages, which tend to be important to reduce inefficiencies associated with on-the-job search. See Section 2.3.2 for more details on how to solve commitment problems in our setting, and Schaal (2012) for a longer discussion and literature review in the context of on-the-job search.
} 


\section{Quantitative Exploration}

The previous section outlined that this model can capture important features at the micro level (e.g. varying job-filling rates) and it is tractable for studying business cycle dynamics with potentially sluggish adjustment of aggregate variables. In this section we calibrate our model to the U.S. labor market in order to investigate how well it is able to quantitatively account for the main features in the data. We first explore the model's cross-sectional properties, showing among other results how it generates differential job-filling rates as in Davis et al. (2013). We then show that the same parameterizations give rise to aggregate sluggishness and other business cycle features. We conclude with a short exploration of the effects of hiring credits for business-cycle stabilization.

\subsection{Calibration}

We briefly sketch the model calibration, referring to Appendix $\mathrm{C}$ for more details. The parameter choices are summarized in Table 1 . We calibrate the model at weekly frequency and choose firm-specific permanent productivities $\left(x_{0}^{i}\right)$ and shares at entry $\left(\sigma^{i}\right)$ to match the firm and employment shares of the Census Bureau's Business Dynamics Statistics (BDS) for the five size classes 1-49, 50-249, $250-999,1000-9999$ and $\geq 10000 .{ }^{26}$ Exit probabilities $\left(\delta^{i}\right)$ are chosen to match annual firm exit rates from the BDS. To capture some features of employment dynamics, we also have a transitory component $x_{1}$ of firm productivity which is redrawn from interval $[1-\bar{x}, 1+\bar{x}]$ with probability $\pi$ in each period. The returns-to-scale parameter $\alpha$ in the production function $x_{0} x_{1} L^{\alpha}$ is calibrated to yield a plausible labor income share.

\footnotetext{
${ }^{26}$ We calibrate the model to match the size distribution of firms (rather than establishments). We note that those results relating to establishment-level statistics (e.g. Figure 3) are robust when we restrict the model sample to the first three size classes which largely represent oneestablishment businesses.
} 
Table 1: Parameter choices in the benchmark calibration.

\begin{tabular}{|c|c|l|}
\hline Parameter & Value & Description \\
\hline$\beta$ & 0.999 & Annual interest rate $5 \%$ \\
$k$ & 6.276 & Matching function scale parameter \\
$r$ & 1.057 & Matching function elasticity parameter \\
$\alpha$ & 0.7 & Production function elasticity \\
$c$ & 8.317 & Recruitment cost scale parameter \\
$\gamma$ & 2 & Recruitment cost elasticity parameter \\
$\left(x_{0}^{i}\right)$ & $(.366, .736,1.166,2.031,4.138)$ & Employment shares (5 size classes) \\
$\left(\sigma^{i}\right)$ & $(98.82,1.0, .153, .025, .002) \%$ & Firm shares $(5$ size classes $)$ \\
$\left(\delta^{i}\right)$ & $(1.71, .27, .16, .088, .016) \% 0$ & Exit rates \\
$\bar{x}$ & 0.312 & Transitory productivity range \\
$\pi$ & 0.027 & Adjustment probability \\
$b$ & 0.1 & Unemployment income $(b / w \approx 0.7)$ \\
$K$ & 329.6 & Entry cost \\
$s_{0}$ & $0.48 \%$ & Quit rate \\
\hline
\end{tabular}

For the recruitment technology, we choose the employment-scaled form ${ }^{27}$ $C(V, L, x)=\frac{c}{1+\gamma}\left(\frac{V}{L}\right)^{\gamma} V$. In our benchmark calibration we take a cubic function $(\gamma=2)$. While this relates to Merz and Yashiv (2007) who estimate a similar cubic hiring technology, ${ }^{28}$ we take an agnostic view about this parameter value. Therefore, we compare the benchmark results with those obtained with a nearly linear recruitment technology $(\gamma=0.1)$ and with a much higher elasticity $(\gamma=8)$. In all versions, the scale parameter $c$ is calibrated to match our target for the weekly job-filling rate.

Unemployment income $b$ is set at roughly 0.7 of the average wage which corresponds to the calibrated value of non-market work chosen by Hall and Milgrom (2008) and Pissarides (2009). Since wages are rather close to the average employment-weighted marginal product, this unemployment value equals 67 percent of marginal product and 47 percent of labor productivity. As this value

\footnotetext{
${ }^{27}$ To avoid division by zero at entrant firms, we assume that actual labor input $\tilde{L}=1+L$ is the sum of the labor inputs of the (single) owner and of the employed workers.

${ }^{28}$ As mentioned before (footnote 7 ), their estimation results are not applicable to our model.
} 
of $b$ implies rather small labor market responses to aggregate shocks, we also consider a much higher unemployment value, namely 97.7 percent of the average wage which corresponds to the choice of Hagedorn and Manovskii (2008) and generates more amplification. While we report the cross-sectional results for the benchmark value of $b$, further robustness regarding this parameter, as well as regarding the returns-to-scale parameter, is explored in Appendix D.

\subsection{Cross-Sectional Implications}

We first simulate the model for a stationary cross-section of firms. Besides matching the calibration targets, our model generates negative relationships between firm size and the shares of younger firms in the cross-sectional distribution (see Table 2) which are roughly in line with the data. Particularly, the model can generate the observation that a substantial share of large firms is rather young which indicates that some firms are able to grow quickly (cf. Luttmer (2011)). This is also confirmed in Figure 2 which shows that the model does a good job in matching the firm-age distribution.
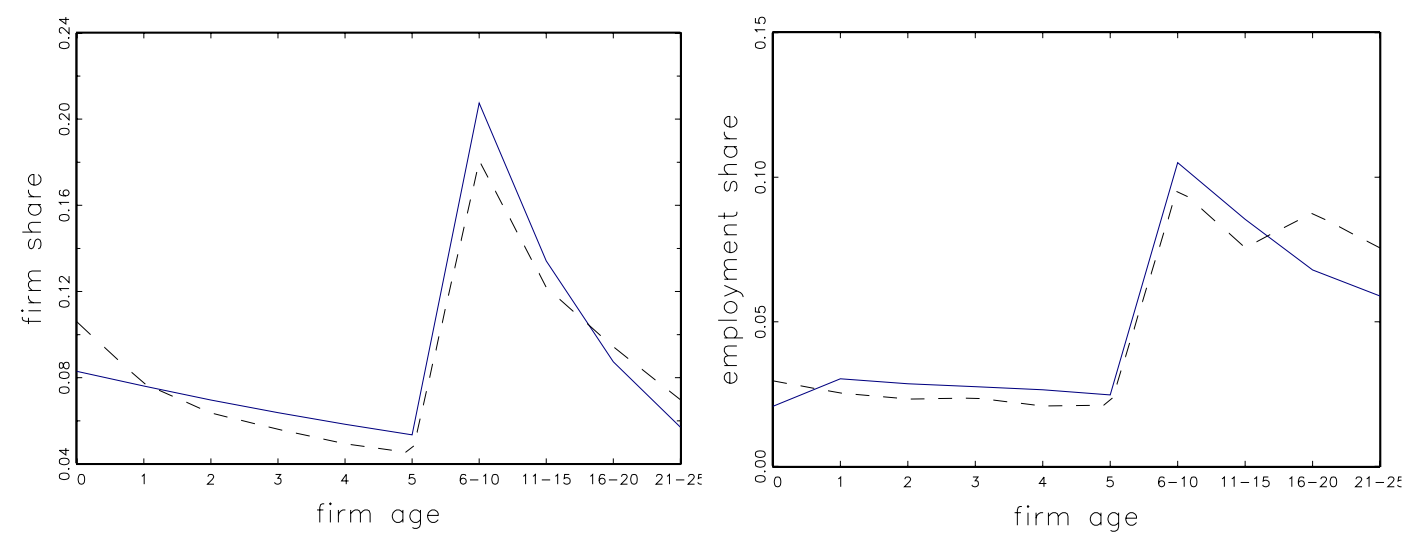

Figure 2: Cross-sectional relationships between firm age in years and firm/employment shares. The dashed curves are from the Business Dynamics Statistics of the Census Bureau for the year 2005. Model statistics (solid) are from a cross section of $4.9 \cdot 10^{6}$ firms for the benchmark model $(\gamma=2)$. 
Table 2: Firm size and employment distribution

\begin{tabular}{|l|ccccc|}
\hline Size class & $1-49$ & $50-249$ & $250-999$ & $1000-9999$ & $\geq 10000$ \\
\hline \hline Data & \multicolumn{5}{|c|}{} \\
\hline Firm shares & 95.62 & 3.64 & 0.54 & 0.17 & 0.02 \\
Employment shares & 29.31 & 16.23 & 10.88 & 17.64 & 25.93 \\
\% younger than 2 yrs. & 24.68 & 7.24 & 4.38 & 2.26 & 1.08 \\
\% younger than 5 yrs. & 39.71 & 16.88 & 10.19 & 5.35 & 3.65 \\
\% younger than 10 yrs. & 57.76 & 31.30 & 20.23 & 12.01 & 7.14 \\
\hline \hline Model & \multicolumn{5}{|c}{} \\
\hline Firm shares & 95.85 & 3.41 & 0.55 & 0.17 & 0.02 \\
Employment shares & 29.77 & 15.71 & 11.33 & 18.78 & 24.41 \\
\% younger than 2 yrs. & 16.16 & 2.99 & 2.35 & 1.77 & 1.48 \\
\% younger than 5 yrs. & 35.53 & 8.46 & 6.96 & 5.32 & 4.62 \\
\% younger than 10 yrs. & 58.31 & 16.88 & 13.92 & 11.11 & 9.85 \\
\hline
\end{tabular}

Notes: The top two rows report firm and employment shares in five size classes (calibrated). The bottom rows are the shares of younger firms in these classes. Data statistics are from the Business Dynamics Statistics of the Census Bureau for the year 2005. Model statistics are from a cross section of $4.9 \cdot 10^{6}$ firms for the benchmark model $(\gamma=2)$.

Our model can also account for the observation that job creation and destruction rates are falling in firm size, although less strongly than in the data. Similar negative relationships between firm size and job flows are obtained at entrant and exiting firms (see Table 6 in Appendix C). Table 3 shows the distribution of quarterly employment growth rates across firms. Our model performs reasonably well in reproducing the overall pattern that more than half of employment is at firms that grow or shrink by more than five percent in a quarter.

One dimension of particular interest is the relationship between employment growth, the vacancy rate and the vacancy yield, which are positively related for growing firms in the Job Openings and Labor Turnover Survey (JOLTS), see Davis et al. (2013). This indicates that the matching rate varies across firms, a feature that is not present in most standard models. To see whether our model can trace this relationship quantitatively, we calculate monthly model statistics 
Table 3: Distribution of employment growth

\begin{tabular}{|c|c|c|}
\hline Growth rate interval & Data & Model $(\gamma=2)$ \\
\hline-2 (exit) & 0.7 & 0.4 \\
$(-2,-0.2]$ & 7.5 & 8.8 \\
$(-0.2,-0.05]$ & 16.5 & 16.3 \\
$(-0.05,-0.02]$ & 9.6 & 5.0 \\
$(-0.02,0.02)$ & 30.9 & 31.4 \\
{$[0.02,0.05)$} & 9.9 & 8.9 \\
{$[0.05,0.2)$} & 16.7 & 16.1 \\
{$[0.2,2)$} & 7.5 & 13.1 \\
2 (entry) & 0.7 & 0.1 \\
\hline
\end{tabular}

Notes: The table reports employment shares for intervals of quarterly employment growth rates. The empirical distribution is taken from Table 2 of Davis et al. (2010). Model statistics are calculated for the benchmark calibration from a cross-section of $4.9 \cdot 10^{6}$ firms.

for hires, vacancies, layoffs and employment growth rates. ${ }^{29}$ Figure 3 shows the cross-sectional relationships from the data and for the three parameterizations of our model. ${ }^{30}$ In the data, firms grow larger both by posting more vacancies and by filling vacancies faster, with the vacancy yield accounting for most of the variation. The benchmark calibration with a cubic recruitment cost function can account for around two thirds of the observed variation in vacancy yields (see the blue (solid) curve in the upper right graph). Employers that expand more rapidly offer more attractive contracts and fill these vacancies faster. There can be many different reasons why vacancy yields are higher in faster-growing firms. For example, strongly expanding firms may search more intensively or they may use alternative recruitment channels. Time aggregation can also account for part of this variation; see Davis et al. (2013) for a discussion. Our benchmark

\footnotetext{
${ }^{29}$ When $L_{t-1}$ and $V_{t-1}$ denotes employment and vacancies at the end of month $t-1$ and $H_{t}$ are hires during month $t$, the hires rate is $h_{t}=H_{t} / L_{t-1}$, the vacancy rate is $v_{t-1}^{r}=V_{t-1} / L_{t-1}$ and the vacancy yield is $v_{t}^{y}=H_{t} / V_{t-1}$, so that $h_{t}=v_{t-1}^{r} v_{t}^{y}$. We use this definition, which is slightly different from Davis et al. (2013), for the model and data statistics. We are grateful to Jason Faberman for providing these data.

${ }^{30}$ To smooth the relationships, all figures in the graphs are calculated as five-bin centered moving averages, as in Davis et al. (2013).
} 
results suggest that competitive search can be one important, but perhaps not the only, mechanism responsible for the observed heterogeneity in vacancy yields and vacancy rates. ${ }^{31}$
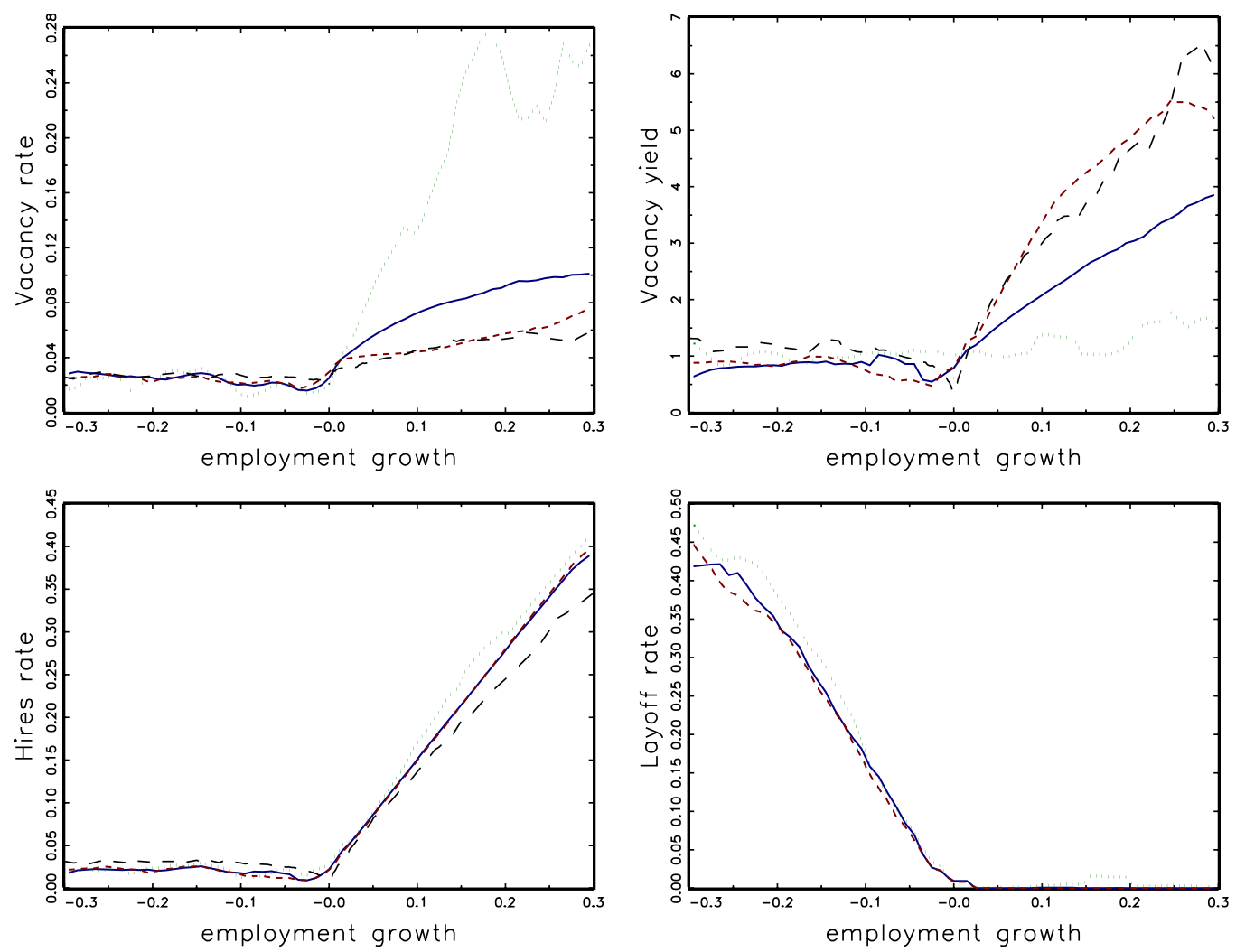

Figure 3: Cross-sectional relationships between monthly employment growth and the vacancy rate, the vacancy yield, the hires rate and the layoff rate. The dashed curves (in the first three graphs) are from the data used in Davis et al. (2013), the blue (solid) curves are for the model with cubic recruitment costs $(\gamma=2)$, the green (dotted) curves are for $\gamma=0.1$ and the red (closely dashed) curves are for $\gamma=8$. Model statistics are calculated from a cross-section of $4.9 \cdot 10^{6}$ firms.

Figure 3 further shows the results for the nearly linear recruitment technology

\footnotetext{
${ }^{31}$ Venkateswaran (2013) considers idiosyncratic shocks to the matching technology to account for the correlation between employment growth and vacancy yields. To what extent fast-growing firms use higher wages to fill their jobs faster cannot be answered for US firms due to lack of firm-level wage data. It should be interesting, however, to explore this question for European countries where matched employer-employee data (combined with firm-level vacancy numbers) are available.
} 
$(\gamma=0.1)$ and for the one with higher curvature $(\gamma=8)$. With linear vacancy costs, weekly vacancy yields $m$ are constant and hence do not vary with employment growth. Variations in the monthly vacancy yield are solely explained by time aggregation. The green (dotted) curve in the upper right graph of Figure 3 shows that the vacancy yield is indeed nearly flat for employment growth below 20 percent. Time aggregation (i.e., firms post and fill unrecorded vacancies during the month) accounts for the variation in vacancy yields beyond that point. On the other hand, as indicated by the red (closely dashed) curves in the figure, our model can principally account for the full variation in vacancy yields and vacancy rates if the curvature of the recruitment technology is sufficiently large. On a related note, Davis et al. (2013) show that vacancy yields (and vacancy rates) vary substantially by industry and employer size groups. While we have not introduced industry-specific parameters into our model, we can study the effect of size and find that smaller employers indeed have higher vacancy yields, albeit the variation is smaller than in the data. Specifically, in our benchmark calibration the vacancy yield at firms with less than 50 workers exceeds the one at firms with more than 500 workers by 10 percent, while in the data the difference is almost a factor of two. ${ }^{32}$

The bottom graphs in Figure 3 show that our model largely accounts for the relationships between employment growth, hires rates and layoff rates, both for growing and for shrinking firms, and regardless of the curvature parameter in the recruitment technology. ${ }^{33}$

\footnotetext{
${ }^{32}$ We expect that more flexible forms of the recruitment technology should give larger variation by employer size: for instance, if $C$ had decreasing returns in $(V, L)$, vacancy postings in larger firms would be less costly so that these firms prefer to recruit less intensively, reducing job-filling rates further.

${ }^{33}$ For the empirical relationship between employment growth and layoffs, see Davis et al. (2010) who find that layoffs dominate quits for large employment contractions. In our model, the quit rate is exogenous at $s_{0}$ so that variations in layoffs necessarily capture all variations in separations.
} 


\subsection{The Business Cycle}

To explore business cycle dynamics, we feed in aggregate productivity shocks and solve the model as outlined in Section 2.3.1. Here we compare two parameterizations of this model, one with the benchmark value of unemployment income and the other with a higher value of $b$ (see the previous discussion). The aggregate productivity parameter can attain one of five equally distant values in the interval $\left[z_{\text {min }}, 2-z_{\text {min }}\right]$, and the Markov process for $z$ is a mean-reverting process with transition probability $\psi$, as described in Appendix C of Shimer (2005). The two parameters $\left(z_{\min }, \psi\right)=(0.93,0.015)$ are set to match a quarterly standard deviation and autocorrelation of labor productivity around trend of 0.015 and 0.76 . We allow the entry cost $K$ to vary with the aggregate state, so as to stabilize the volatility of job creation at opening firms. For further details, see Appendix C.

Table 4 shows the outcome of this experiment for volatility and comovement with aggregate output. While both parameterizations reproduce the observed comovement with output, only the calibration with high opportunity cost of work is able to generate amplification of labor market variables which is of a similar order of magnitude as in the data. Relative to a model with homogeneous firms (Hagedorn and Manovskii (2008)), firm heterogeneity and decreasing returns seem to add no more amplification. ${ }^{34}$ In terms of correlation patterns, our model produces procyclical job-finding rates and countercyclical separation rates. We also note that the correlation between labor productivity and the job-finding rate is positive but imperfect. This contrasts with Shimer's (2005) calibration of the standard search and matching model with homogeneous firms where this correlation is perfect, and we will elaborate below on differences in the propagation of shocks. ${ }^{35}$

\footnotetext{
${ }^{34}$ This is consistent with Krause and Lubik (2007), Faccini and Ortigueira (2010) and Hawkins (2011) who obtain little amplification of technology shocks in labor market models with multiworker firms and intra-firm bargaining.

${ }^{35}$ The model correlations between labor productivity and the job-finding rate are 0.30 (low
} 
Table 4: Business cycle statistics

\begin{tabular}{|r|c|c|c|c|c|c|}
\hline & \multicolumn{2}{|c|}{ Data } & \multicolumn{2}{c|}{ Model (low b) } & \multicolumn{2}{c|}{ Model (high $b$ ) } \\
\hline & $\begin{array}{c}\text { Rel. } \\
\text { vol. }\end{array}$ & $\begin{array}{c}\text { Corr. w. } \\
\text { output }\end{array}$ & $\begin{array}{c}\text { Rel. } \\
\text { vol. }\end{array}$ & $\begin{array}{c}\text { Corr. w. } \\
\text { output }\end{array}$ & $\begin{array}{c}\text { Rel. } \\
\text { vol. }\end{array}$ & $\begin{array}{c}\text { Corr. w. } \\
\text { output }\end{array}$ \\
\hline Productivity & 0.67 & 0.885 & 0.93 & 0.970 & 0.66 & 0.930 \\
Unemployment & 6.55 & -0.829 & 2.88 & -0.381 & 6.16 & -0.827 \\
Vacancies & 6.81 & 0.428 & 1.20 & 0.390 & 3.93 & 0.506 \\
Job-finding rate & 3.86 & 0.812 & 1.15 & 0.484 & 3.06 & 0.884 \\
Separation rate & 2.67 & -0.575 & 2.66 & -0.230 & 3.39 & -0.782 \\
Vacancy yield & 5.88 & -0.790 & 1.54 & -0.639 & 4.80 & -0.941 \\
Recruiting intensity & 1.00 & 0.871 & 0.56 & 0.340 & 1.37 & 0.841 \\
\hline
\end{tabular}

Notes: All variables are logged and HP filtered with parameter 1600. Relative volatility measures the standard deviation of a variable divided by the standard deviation of output. Data are for the U.S. labor market (1951-2011), except the job-finding rate and separation rate series (1951-2007) which were constructed by Robert Shimer (see Shimer (2012) and his webpage http://sites.google.com/site/robertshimer/research/flows) and the vacancy yields and recruiting intensity series (2001-2011) which were constructed by Davis et al. (2013). Monthly series are converted in quarterly series by time averaging. The model statistics are obtained from 20 simulations of $5 \cdot 10^{5}$ firms over a period of 2080 weeks. Weekly series are converted into quarterly series by time averaging.

The last two rows of Table 4 show that our model captures the volatility and comovement of the aggregate vacancy yield and of the recruiting intensity as calculated by Davis et al. (2013) for JOLTS data, 2001-2011. In particular, we can decompose the aggregate vacancy yield as

$$
\frac{\bar{H}}{\bar{V}}=\tilde{m}(\bar{\lambda}) \sum_{i} \frac{m_{i}}{\tilde{m}(\bar{\lambda})} \frac{V_{i}}{\bar{V}} \equiv \tilde{m}(\bar{\lambda}) r
$$

where $\bar{H}, \bar{V}$ are aggregate hires and vacancies, $\bar{\lambda}$ is the aggregate unemploymentvacancy ratio, $\tilde{m}$ is the reduced-form matching function (that is, the inverse of $\lambda($.$) , cf. footnote 10), and \left(m_{i}, V_{i}\right)$ are recruitment policies of firm $i$. Since $\bar{\lambda}$ is countercyclical, so is the aggregate vacancy yield, although less than a standard b) and 0.79 (high b), while the data counterpart (1951-2007) is 0.56 . 
aggregate matching function would predict. The term $r$ in equation (19) is a measure of the (vacancy-weighted) "recruiting intensity" which turns out to be procyclical, both in the data and in the model with $\gamma=2 .{ }^{36}$ The reason why $r$ is procyclical in our model is that $\tilde{m}$ is concave and that the cross-sectional dispersion of $\lambda_{i}\left(m_{i}\right)$ is countercyclical. ${ }^{37}$

To give a brief impression of the cyclicality of wages we have to take a stance on the wage profile over time. Although our theory determines mainly the present value of wages, consider flat wage contracts as an empirically relevant special case. With this specification, we find that aggregate wages are procyclical and rigid, while wages for new hires are more volatile. In particular, the elasticity of wages for all workers (new hires) with respect to productivity is $0.06(0.60)$ for the calibration with high unemployment income, which compares with the estimates of Haefke et al. (2013) who report elasticities in the range 0.1-0.3 (0.61). Other implementations are clearly conceivable that would give rise to greater wage cyclicality, but it is good to know that our model can account for substantial wage rigidity.

Finally, we illustrate the role of recruitment frictions for propagation of aggregate shocks by considering the model response to a permanent increase in the aggregate productivity parameter by one percent. In response to such a shock, we let entry costs increase by the same factor. ${ }^{38}$ The new steady-state equilib-

\footnotetext{
${ }^{36}$ Our measure of the recruiting intensity corresponds to the variable $\bar{q}_{t}^{1-\alpha}$ in equation (9) of Davis et al. (2013). We set $\alpha=0.5$ as in their paper to calculate the moments in Table 4.

${ }^{37}$ This seems consistent with the observation of Davis et al. (2012) that the cross-industry dispersion of job-filling rates increased during the Great Recession. We note that the procyclicality of $r$ vanishes in our model with nearly linear recruitment costs $(\gamma=0.1)$ because all firms fill vacancies at the same matching rate.

${ }^{38}$ Without the proportional increase in entry costs, firm entry would exhibit an implausible spike at the time of the shock. There are many reasons why entry costs vary with the business cycle, e.g. procyclical rental rates, capital prices, or outside opportunities of entrepreneurs. Regarding the latter, endogenous entrepreneurship could be easily introduced in our framework when unemployed workers have the option to either search for jobs or to start a business. We expect that efficiency and tractability would be preserved.
} 
rium features more firms and higher aggregate output. In Figure 4, we compare impulse responses for the three calibrations with different curvature parameters, where unemployment income is set to the high value. Relative to the model with nearly linear recruitment costs, convex costs generate a pronounced labor market propagation, featuring sluggish adjustments of the job-finding rate and of the vacancy-unemployment ratio, which are similar to the responses of these variables to a permanent productivity shock in vector autoregressions (see Appendix E for details). Fujita and Ramey (2007) and Shimer (2005) argue that standard search and matching models cannot generate such patterns because market tightness and the job-finding rate are jump variables which correlate perfectly with aggregate productivity. ${ }^{39}$ The bottom graphs in Figure 4 show that this is also true in our model when vacancy costs are linear, ${ }^{40}$ but not when they are convex in which case both variables lag behind aggregate productivity by 2-3 quarters.

We emphasize that the sluggish model dynamics come about for the same parameterizations of the recruitment technology which also give rise to plausible variations of vacancy yields across firms. Micro-level features are thus directly linked to the dynamics at the aggregate level. Lagged responses to productivity shocks are neither picked up by most (homogeneous worker) random search models, nor by existing models with directed search, such as Shi (2009), Menzio and Shi (2010, 2011), and Schaal (2012). In our model, convexity of recruitment technologies in combination with the entry of new firms contribute to the delayed response of the labor market: the positive shock triggers a surge of entrant firms who create only few jobs when they are small but more as they grow larger. With linear recruitment costs, all firms (young and old) would directly jump to their

\footnotetext{
${ }^{39}$ There may be other departures from the standard model that break this result. By adding worker heterogeneity, for example, the composition of workers in the unemployment pool determines the aggregate job-finding rate (cf. Robin (2011)) which may contribute to persistent dynamics.

${ }^{40}$ Equation (16) implies that $m$ is a function of the aggregate state $\mu_{i}$ alone if marginal vacancy costs are constant.
} 

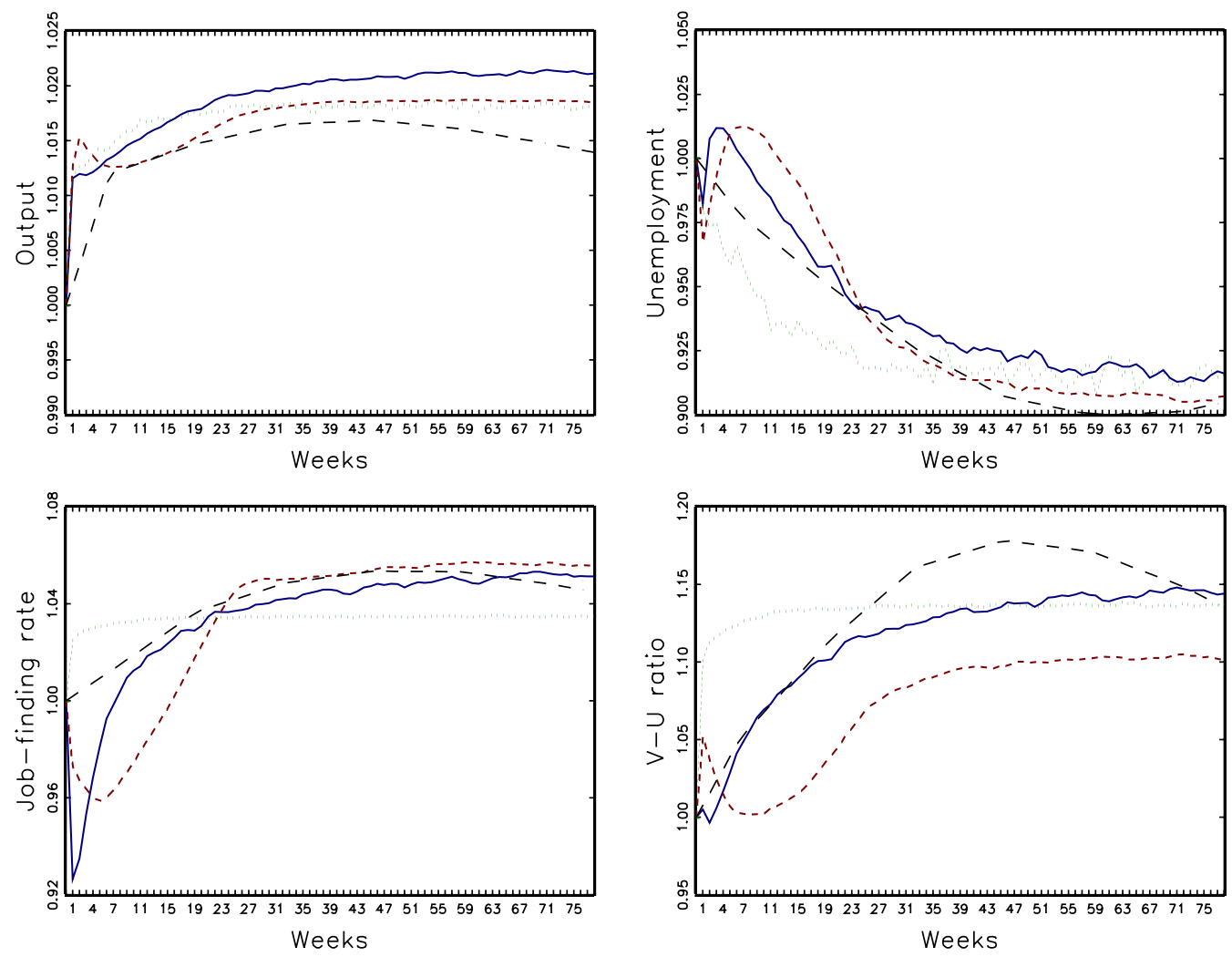

Figure 4: Impulse response to a permanent $1 \%$ increase in aggregate productivity. The dashed curves are responses from a VAR for U.S. data (see Appendix E for details), the blue (solid) curves are for the model with cubic recruitment costs $(\gamma=2)$, the green (dotted) curves are for $\gamma=0.1$ and the red (closely dashed) curves are for $\gamma=8$. All three versions have unemployment income $b \approx 0.977 \cdot w$.

optimal sizes.

\subsection{Policy Experiment: The Effects of Hiring Subsidies}

We provide some first exploration of the positive implications of policy interventions in our environment. We focus on hiring subsidies (hiring credits) which have been extensively deployed to stimulate job growth in past recessions and have re- 
ceived renewed attention during the Great Recession. ${ }^{41}$ It might be conjectured that they stabilize business cycle fluctuations, especially when they are used in a counter-cyclical manner. However, we find that this is not the case. We compare time-invariant and counter-cyclical subsidies, financed by lump-sum taxes. The model is solved as the solution to a quasi-planner's problem who maximizes social welfare subject to given government policy (cf. Veracierto (2008)). We set the subsidy per hire to 0.015 which corresponds to $3.4 \%$ of a monthly wage so that government expenditures on hiring subsidies are 0.1 percent of output. With a counter-cyclical policy, hiring firms receive the subsidy only when the aggregate productivity state is below its mean. Since our model calibration with a high value of unemployment benefits generates more plausible aggregate dynamics, we use this calibrated version for the policy experiments.

Table 5 shows the outcome of the policy simulations. While both policies succeed in stabilizing the job-finding rate to some extent, they considerably increase the volatility of separations, so that they are not successful to stabilize unemployment fluctuations. Perhaps surprisingly, the destabilizing forces are stronger for the counter-cyclical policy which ultimately yields higher unemployment volatility compared to a laissez-faire situation.

The intuition for these findings is that hiring subsidies make firms more prone to fire their employees in adverse idiosyncratic or aggregate states, i.e., labor hoarding is less beneficial. Firms optimally decide to lay off more workers since wages increase in response to the policy, which happens because entrant firms continue to make zero expected profits and the subsidy gets passed through into increased wages. Higher wages make firms more eager to fire in bad states and the subsidy makes them more eager to hire in good states. Even in steady state

\footnotetext{
${ }^{41}$ The Hiring Incentives to Restore Employment Act (HIRE) of 2010 includes tax exemptions from employer social security contributions and business income tax breaks for workers hired from unemployment; hiring credits were also an element of the American Jobs Act proposed by the Obama administration in 2011. For an overview, see Neumark (2013).
} 
Table 5: Business cycle effects of hiring subsidies

\begin{tabular}{|r|c|c|c|}
\hline & $\begin{array}{c}\text { Laissez } \\
\text { faire }\end{array}$ & $\begin{array}{c}\text { Stationary } \\
\text { policy }\end{array}$ & $\begin{array}{c}\text { Cyclical } \\
\text { policy }\end{array}$ \\
\hline Unemployment & 15.5 & 15.5 & 16.3 \\
Vacancies & 9.8 & 7.1 & 8.2 \\
Output & 2.5 & 2.4 & 2.4 \\
Job-finding rate & 7.7 & 6.0 & 6.0 \\
Separation rate & 8.5 & 11.2 & 11.8 \\
\hline
\end{tabular}

Notes: The table reports the standard deviations of logged and HP filtered (parameter 1600) quarterly variables, where model statistics are obtained as in Table 4.

with only idiosyncratic shocks, both the separation and the hiring rate increase by 8 percent in response to the (time-invariant) policy, which results in more worker reallocation between employment and unemployment, so that the steadystate unemployment rate increases by half a percentage point. Over the business cycle, time-invariant hiring subsidies induce firms to fire more workers for any given productivity level, because wages rise in all aggregate states. This is illustrated in Figure 5(a) which shows the employment growth policy of a particular firm (the one with median transitory and permanent idiosyncratic productivity), both in the lowest and in the highest aggregate state. For a given employment level, separations are higher under the policy (dashed curves) than under laissez faire (solid curves). At the same time, firms grow to a smaller size in the lowproductivity state, though not in the high-productivity state. This explains why separations are more volatile under the stationary policy compared to laissezfaire. The volatility of separations increases further under the cyclical policy which leads to higher wages in the lowest aggregate states only. Hence firms find it optimal to lay off more workers during recessions and fewer workers during booms, which is shown in Figure 5(b) where separations increase only in the low-productivity state.

These findings suggest that hiring subsidies are not particularly useful to sta- 


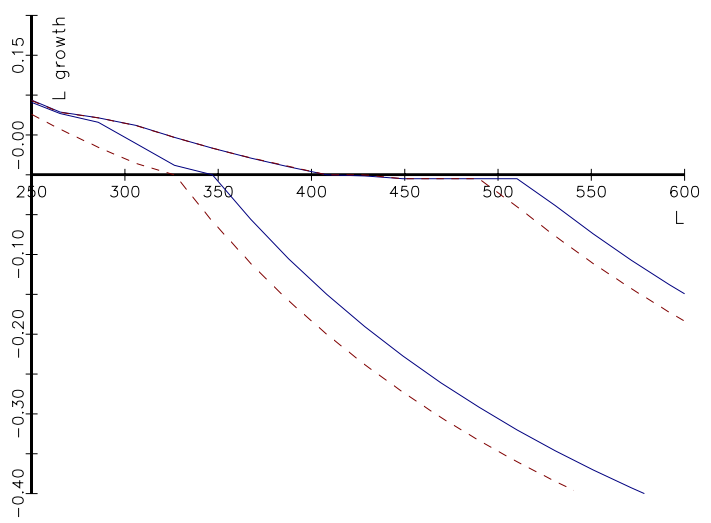

(a) Stationary policy

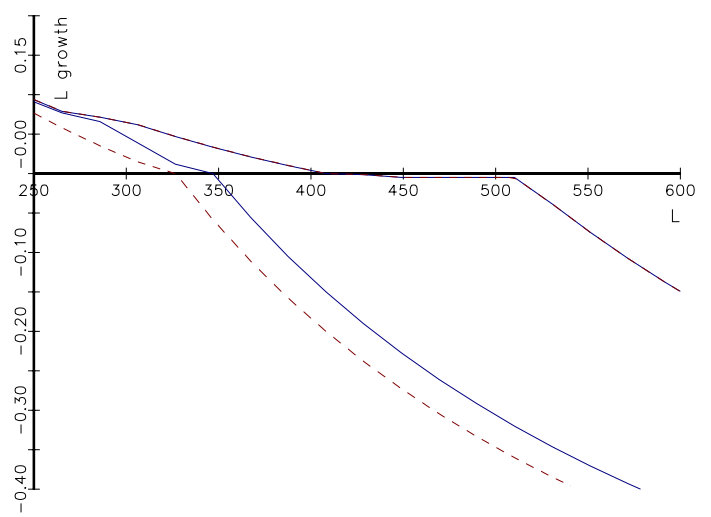

(b) Cyclical policy

Figure 5: Employment growth for varying employment levels of an exemplary firm in the lowest and in the highest aggregate productivity state. The solid (blue) curves are under laissez faire. The dashed (red) curves are with stationary hiring subsidies (left graph) and with cyclical subsidies (right graph).

bilize the cycle, at least when they are not accompanied by additional policies aiming to dampen separations during recessions. More work on these issues will obviously be needed to explore the impact of such policies in broader environments.

\section{Conclusions}

This paper investigates job reallocation in a model where firms actively compete for workers in a frictional labor market. Meaningful dynamics arise when firms cannot instantly post vacancies at constant marginal costs - for example because existing workers are required for recruitment. Firms that want to expand quickly are willing to pay higher salaries to attract more workers and hence fill vacancies faster. Matching rates are therefore not an aggregate object, as in most of the search literature, but are firm-specific as recently documented by Davis et al. (2013). Calibrated versions of the model show that it can account 
for this variation in vacancy yields, alongside other cross-sectional features. The same reasons that induce firms to vary their vacancy yields also induce delayed aggregate responses of key labor market variables to productivity shocks.

These applied contributions are derived within a model that extends competitive search to a setting with large firms that face decreasing returns in production and convex costs in recruitment. This model provides an alternative to the current workhorse models for large firms in search markets which are based on random search and bargaining. We establish substantial differences between these environments: Competition for workers induces firm-specific matching rates, while they are identical in random-search models. Multi-worker firms in that environment always engage in inefficient hiring, whereas we show that our setting retains the efficiency properties known from wage competition among single-worker firms. Finally, our model remains tractable both in and out of steady state, which makes it useful for applied purposes. All our insights apply equivalently to a model where workers are risk averse but have access to full insurance markets. As discussed in the extensions, we expect our main tools to be applicable in the absence of such insurance markets, albeit at the loss of efficiency. Such an extension would make policy analysis more relevant.

\section{References}

Acemoglu, D. and W. Hawkins (2014), "Search with multi-worker firms." Theoretical Economics, 9, 583-628.

Acemoglu, D. and R. Shimer (1999), "Efficient unemployment insurance." Journal of Political Economy, 107, 893-928.

Amir, R. (1996), "Sensitivity analysis of multisector optimal economic dynamics." Journal of Mathematical Economics, 25, 123-141. 
Belzil, C. (2000), "Job creation and job destruction, worker reallocation, and wages." Journal of Labor Economics, 18, 183-203.

Bentolila, S. and G. Bertola (1990), "Firing costs and labour demand: How bad is Eurosclerosis?" Review of Economic Studies, 57, 381-402.

Bertola, G. and R. Caballero (1994), "Cross-sectional efficiency and labour hoarding in a matching model of unemployment." Review of Economic Studies, $61,435-456$.

Blatter, M., S. Muehlmann, and S. Schenker (2012), "The costs of hiring skilled workers." European Economic Review, 56, 20-35.

Brown, C. and J. Medoff (2003), "Firm age and wages." Journal of Labor Economics, 21, 677-697.

Burdett, K. and D. Mortensen (1998), "Wage differentials, employer size and unemployment." International Economic Review, 39, 257-273.

Burdett, K., S. Shi, and R. Wright (2001), "Pricing and matching with frictions." Journal of Political Economy, 109, 1060-1085.

Cooper, R., J. Haltiwanger, and J. Willis (2007), "Search frictions: Matching aggregate and establishment observations." Journal of Monetary Economics, $54,56-78$.

Davis, S., J. Faberman, and J. Haltiwanger (2012), "Recruiting intensity during and after the Great Recession: National and industry evidence." American Economic Review, 102, 584-588.

Davis, S., J. Faberman, and J. Haltiwanger (2013), "The establishment-level behavior of vacancies and hiring." Quarterly Journal of Economics, 128, 581622.

Davis, S., J. Faberman, J. Haltiwanger, and I. Rucker (2010), “Adjusted estimates of worker flows and job openings in JOLTS." In Labor in the New Economy (K. Abraham, J. Spletzer, and M. Harper, eds.), 187-216, University of Chicago Press, Chicago. 
Ebell, M. and C. Haefke (2009), "Product market deregulation and the US employment miracle." Review of Economic Dynamics, 12, 479-504.

Eeckhout, J. and P. Kircher (2012), "Assortative matching with large firms - span of control over more versus better workers." Unpublished Manuscript.

Elsby, M. and R. Michaels (2013), "Marginal jobs, heterogenous firms, and unemployment flows." American Economic Journal: Macroeconomics, 5, 1-48.

Faccini, R. and S. Ortigueira (2010), "Labor-market volatility in the search-andmatching model: The role of investment-specific technology shocks." Journal of Economic Dynamics and Control, 34, 1509-1527.

Fujita, S. (2011), "Dynamics of worker flows and vacancies: Evidence from the sign restriction approach." Journal of Applied Econometrics, 26, 89-121.

Fujita, S. and M. Nakajima (2013), "Worker flows and job flows: A quantitative investigation." Working Paper 13-9, Federal Reserve Bank of Philadelphia.

Fujita, S. and G. Ramey (2007), "Job matching and propagation." Journal of Economic Dynamics and Control, 31, 3671-3698.

Galenianos, M. and P. Kircher (2009), "Directed search with multiple job applications." Journal of Economic Theory, 114, 445-471.

Garibaldi, P., E. Moen, and D. Sommervoll (2014), "Competitive on-the-job search." CEPR Discussion Paper No. 10175.

Geromichalos, A. (2012), "Directed search and optimal production." Journal of Economic Theory, 147, 2303-2331.

Godenhielm, M. and K. Kultti (2014), "Directed search with endogenous capacity." Unpublished Manuscript.

Guerrieri, V. (2008), "Inefficient unemployment dynamics under asymmetric information." Journal of Political Economy, 116, 667-708.

Guerrieri, V., R. Shimer, and R. Wright (2010), "Adverse selection in competitive search equilibrium." Econometrica, 78, 1823-1862.

Haefke, C., M. Sonntag, and T. van Rens (2013), "Wage rigidity and job cre- 
ation." Journal of Monetary Economics, 60, 887-899.

Hagedorn, M. and I. Manovskii (2008), "The cyclical behavior of equilibrium unemployment and vacancies revisited." American Economic Review, 98, 16921706.

Hall, R. and P. Milgrom (2008), "The limited influence of unemployment on the wage bargain." American Economic Review, 98, 1653-1674.

Haltiwanger, J., R. Jarmin, and J. Miranda (2013), "Who creates jobs? Small versus large versus young." Review of Economics and Statistics, 95, 347-361.

Hawkins, W. (2011), "Do large-firm bargaining models amplify and propagate aggregate productivity shocks?" Unpublished Manuscript.

Hawkins, W. (2013), "Competitive search, efficiency, and multi-worker firms." International Economic Review, 54, 219-251.

Hawkins, W. (2014), "Bargaining with commitment between workers and large firms." Forthcoming in Review of Economic Dynamics.

Helpman, E. and O. Itskhoki (2010), "Labor market rigidities, trade and unemployment." Review of Economic Studies, 77, 1100-1137.

Hopenhayn, H. and R. Rogerson (1993), "Job turnover and policy evaluation: A general equilibrium analysis." Journal of Political Economy, 101, 915-938.

Hosios, A. (1990), "On the efficiency of matching and related models of search and unemployment." Review of Economic Studies, 57, 279-298.

Koeniger, W. and J. Prat (2007), "Employment protection, product market regulation and firm selection." Economic Journal, 117, F302-F332.

Krause, M. and T. Lubik (2007), "Does intra-firm bargaining matter for business cycle dynamics?" Deutsche Bundesbank Discussion Paper 17/2007.

Krusell, P. and A. Smith (1998), "Income and wealth heterogeneity in the macroeconomy." Journal of Political Economy, 106, 867-896.

Lentz, R. and D. Mortensen (2012), "Labor market friction, firm heterogeneity, and aggregate employment and productivity." Unpublished Manuscript. 
Lester, B. (2010), "Directed search with multi-vacancy firms." Journal of Economic Theory, 145, 2108-2132.

Luttmer, E. (2011), "On the mechanics of firm growth." Review of Economic Studies, 78, 1042-1068.

Menzio, G. and E. Moen (2010), "Worker replacement." Journal of Monetary Economics, 57, 623-636.

Menzio, G. and S. Shi (2010), "Block recursive equilibria for stochastic models of search on the job." Journal of Economic Theory, 145, 1453-1494.

Menzio, G. and S. Shi (2011), "Efficient search on the job and the business cycle." Journal of Political Economy, 119, 468-510.

Merz, M. and E. Yashiv (2007), "Labor and the market value of the firm." American Economic Review, 97, 1419-1431.

Moen, E. (1997), "Competitive search equilibrium." Journal of Political Economy, 105, 385-411.

Moscarini, G. and F. Postel-Vinay (2013), "Stochastic search equilibrium." Review of Economic Studies, 80, 1545-1581.

Neumark, D. (2013), "Spurring job creation in response to severe recessions: Reconsidering hiring credits." Journal of Policy Analysis and Management, $32,142-171$.

Pissarides, C. (2000), Equilibrium Unemployment Theory, 2nd edition. The MIT Press, Cambridge, MA.

Pissarides, C. (2009), "The unemployment volatility puzzle: Is wage stickiness the answer?" Econometrica, 77, 1339-1369.

Postel-Vinay, F. and J.-M. Robin (2002), "Equilibrium wage dispersion with worker and employer heterogeneity." Econometrica, 70, 2295-2350.

Robin, J.-M. (2011), "On the dynamics of unemployment and wage distributions." Econometrica, 79, 1327-1355.

Rogerson, R., R. Shimer, and R. Wright (2005), "Search-theoretic models of the 
labor market: A survey." Journal of Economic Literature, 43, 959-988.

Rudanko, L. (2011), "Aggregate and idiosyncratic risk in a frictional labor market." American Economic Review, 101, 2823-2843.

Schaal, E. (2012), "Uncertainty, productivity and unemployment in the Great Recession." Unpublished Manuscript.

Schmieder, J. (2013), "What causes wage dispersion? Evidence from new firms." Unpublished Manuscript.

Shi, S. (2001), "Frictional assignment, I. Efficiency." Journal of Economic Theory, 98, 232-260.

Shi, S. (2009), "Directed search for equilibrium wage-tenure contracts." Econometrica, $77,561-584$.

Shimer, R. (2005), "The cyclical behavior of equilibrium unemployment and vacancies." American Economic Review, 95, 25-49.

Shimer, R. (2010), Labor Markets and Business Cycles. Princeton University Press.

Shimer, R. (2012), "Reassessing the ins and outs of unemployment." Review of Economic Dynamics, 15, 127-148.

Smith, E. (1999), "Search, concave production and optimal firm size." Review of Economic Dynamics, 2, 456-471.

Stole, L. and J. Zwiebel (1996), "Intrafirm bargaining under non-binding contracts." Review of Economic Studies, 63, 375-410.

Venkateswaran, V. (2013), "Heterogeneous information and labor market fluctuations." Unpublished Manuscript.

Veracierto, M. (2008), "Firing costs and business cycle fluctuations." International Economic Review, 49, 1-39. 


\section{Appendix to the paper "Efficient Firm Dynamics in a Frictional Labor Market" by L. Kaas and P. Kircher (For Online Publication)}

\section{Appendix A: Proofs}

Proposition 1: Consider recruitment cost functions satisfying property $(C)$. The firm's value function $J^{x}(L, W)$ is strictly increasing and strictly concave in its workforce $L$, strictly increasing in productivity $x$, strictly supermodular in $(x, L)$ and decreasing in the worker's search value $\rho$. The job-filling rate $m^{x}(L)$ is strictly increasing in productivity $x$ and strictly decreasing in the workforce $L$. Posted vacancies $V^{x}(m, L)$ are increasing in $L$ and strictly increasing in the desired job-filling rate $m$.

Proof of Proposition 1:

Rewrite problem (4) to express the dependence of the value function on $x$ and on the workers' search value $\rho$ as the solution to the dynamic programming problem

$$
\begin{aligned}
J(L, x ; \rho)= & \max _{(m, V) \geq 0} x F(L)-C(V, L, x)-D(m ; \rho) V+\beta(1-\delta) J\left(L_{+}, x ; \rho\right) \\
& \text { s.t. } L_{+}=L(1-s)+m V,
\end{aligned}
$$

where function $D(m ; \rho)$ is defined in the text. It is increasing, strictly convex in $m$ and increasing in $\rho$. This problem is equivalently defined on a compact state space $L \in[0, \bar{L}]$ where $\bar{L}$ is so large that it never binds. This is possible because of the Inada condition $\lim _{L \rightarrow \infty} F^{\prime}(L)=0$. The RHS in problem (20) defines an operator $T$ which maps a continuous function $J_{0}(L, x ; \rho)$, defined on $\mathcal{S}=[0, \bar{L}] \times[0, \bar{x}] \times[0, \bar{\rho}]$ into a continuous function $J_{1}(L, x ; \rho)=T\left(J_{0}\right)(L, x ; \rho)$ defined on the same domain. Here $\bar{x}$ and $\bar{\rho}$ are arbitrary upper bounds on $x$ and $\rho$. Operator $T$ is a contraction, therefore there exists a unique fixed point $J^{*}$ which is a continuous function and which is the limit of any sequence $J_{n}$ defined by $J_{n}=T\left(J_{n-1}\right)$.

Starting from a continuous $J_{0}$ that is differentiable and weakly increasing in $L$ and $x$ and weakly decreasing in $\rho$, successive application of $T$ yields a sequence $J_{n}$ where each element shares these properties. Since the subset of continuous functions on $\mathcal{S}$ that are weakly increasing in $L$ and $x$ and weakly decreasing in $\rho$ is closed under the sup norm, the limit $J^{*}$ of sequence $J_{n}$ is in this set. Because $x F(L)-C(V, L, x)$ is strictly increasing in $(L, x)$ and since $D(m ; \rho)$ is strictly increasing in $\rho$, the limit $J^{*}$ is strictly increasing in $x$ and $L$ and strictly decreasing in $\rho$.

We show in subsequent Lemmata A.1 and A.2 that $T$ maps functions that are differentiable and concave in $L$ and supermodular in $L$ and $x$ into functions with the same properties. Since the subset of concave and supermodular functions is closed, the same 
arguments as above imply that the unique fixed point $J^{*}$ is concave in $L$ and supermodular in $(L, x)$. Since function $x F(L)-C(V, L, x)$ is strictly concave in $L, J^{*}$ is also strictly concave in $L$. Concavity in $L$ and differentiability of $x F(L)-C(V, L, x)$ together with the theorem of Benveniste and Scheinkman establishes differentiability of $J^{*}$ in $L$.

Before we establish the remaining results, rewrite (20) in terms of hirings $H=m V$. Dropping argument $\rho$ from $J$, we can equivalently write (20) as

$$
J(L, x)=\max _{H} x F(L)-\mathcal{C}(H, L, x)+\beta(1-\delta) J(L(1-s)+H, x)
$$

where

$$
\mathcal{C}(H, L, x) \equiv \min _{m} C\left(\frac{H}{m}, L, x\right)+D(m) \frac{H}{m} .
$$

The right hand side of (21) is an equivalent expression of the fixed-point operator $T$. As will become clear, the per period return $x F(L)-\mathcal{C}(H, L, x)$ is supermodular in $(L, H)$, but when $C_{13}>0$ (which arises in first specification in (1) for $h>0$ ) the per period return is strictly submodular in $(H, x)$ and in $\left(L_{+}, x\right)$ when one writes $H=L_{+}-(1-s) L$, which renders standard tools to prove supermodularity (e.g., Amir (1996)) inapplicable. To proceed, the optimality condition for problem (22) is

$$
C_{1}\left(\frac{H}{m}, L, x\right)=D^{\prime}(m) m-D(m) .
$$

Differentiate this equation to obtain

$$
\begin{aligned}
\frac{d m}{d H} & =\frac{C_{11}}{C_{11} \frac{H}{m}+D^{\prime 2}}>0, \\
\frac{d m}{d L} & =\frac{C_{12} m}{C_{11} \frac{H}{m}+D^{\prime 2}}=\frac{C_{12} m}{C_{11}} \frac{d m}{d H} \leq 0, \\
\frac{d m}{d x} & =\frac{C_{13} m}{C_{11} \frac{H}{m}+D^{\prime 2}}=\frac{C_{13} m}{C_{11}} \frac{d m}{d H} \geq 0 .
\end{aligned}
$$


Therefore, we can express the derivatives of cost function $\mathcal{C}$ as

$$
\begin{aligned}
\mathcal{C}_{1} & =D^{\prime}(m)>0, \\
\mathcal{C}_{2} & =C_{2}, \\
\mathcal{C}_{11} & =D^{\prime \prime}(m) \frac{d m}{d H}>0, \\
\mathcal{C}_{12} & =D^{\prime \prime}(m) \frac{d m}{d L} \leq 0, \\
\mathcal{C}_{22} & =C_{22}-C_{12} \frac{H}{m^{2}} \frac{d m}{d L} \\
\mathcal{C}_{13} & =D^{\prime \prime}(m) \frac{d m}{d x} \geq 0, \\
\mathcal{C}_{23} & =C_{23}-C_{12} \frac{H}{m^{2}} \frac{d m}{d x} .
\end{aligned}
$$

Lemma A.1: Suppose that $J$ is twice differentiable and concave in $L$. Then $T(J)$ is twice differentiable and

(a) concave in $L$ if the following condition holds:

$$
\mathcal{C}_{12}^{2}+\mathcal{C}_{11}\left[x F^{\prime \prime}-\mathcal{C}_{22}\right] \leq 0
$$

(b) concave in $L$ and supermodular in $(L, x)$ if $J$ is supermodular in $(L, x)$ and if (32) and the following condition hold:

$$
\mathcal{C}_{12} \mathcal{C}_{13}+\mathcal{C}_{11}\left[F^{\prime}-\mathcal{C}_{23}\right] \geq 0
$$

\section{Lemma A.2:}

(a) Condition (32) holds under the following condition on the original cost function $C$ :

$$
C_{12}^{2}+C_{11}\left[x F^{\prime \prime}-C_{22}\right] \leq 0
$$

(b) Condition (33) holds under the following condition on the original cost function $C$ :

$$
C_{12} C_{13}+C_{11}\left[F^{\prime}-C_{23}\right] \geq 0
$$

\section{Proof of Lemma A.1:}

Consider $T(J)$ defined by the RHS of (21).

Part (a). Since $J$ is a concave and twice differentiable function of $L, T(J)$ is also twice differentiable, and a policy function exists and is differentiable. Differentiate $T(J)$ twice 
with respect to $L$ to obtain

$$
\frac{d^{2}(T(J))}{d L^{2}}=x F^{\prime \prime}-\mathcal{C}_{22}+\beta \varphi(1-s) J_{11}+\left[-\mathcal{C}_{12}+\beta \varphi J_{11}\right] \frac{d H}{d L} .
$$

Differentiate the FOC $\mathcal{C}_{1}=\beta(1-\delta) J_{1}$ with respect to $L$ to obtain

$$
\frac{d H}{d L}=\frac{\beta \varphi J_{11}-\mathcal{C}_{12}}{\mathcal{C}_{11}-\beta(1-\delta) J_{11}}
$$

Substitute this into (36) to obtain

$$
\frac{d^{2}(T(J))}{d L^{2}}=x F^{\prime \prime}-\mathcal{C}_{22}+\frac{\beta \varphi(1-s) J_{11} \mathcal{C}_{11}+\mathcal{C}_{12}^{2}-2 \beta \varphi J_{11} \mathcal{C}_{12}}{\mathcal{C}_{11}-\beta(1-\delta) J_{11}}
$$

In the last term, the denominator is positive and larger than $\mathcal{C}_{11}$. In the numerator, all terms involving $J_{11}$ are negative (due to (27) and (28)); hence the numerator is smaller than $\mathcal{C}_{12}^{2}$. Therefore,

$$
\frac{d^{2}(T(J))}{d L^{2}} \leq x F^{\prime \prime}-\mathcal{C}_{22}+\frac{\mathcal{C}_{12}^{2}}{\mathcal{C}_{11}}
$$

which is non-positive under (32). Hence, $T$ maps a concave and twice differentiable function into a function with the same properties.

Part (b). Since $J$ is a concave, supermodular and twice differentiable function of $(L, x)$, $T(J)$ is twice differentiable and a differentiable policy function exists. Differentiate $T(J)$ twice with respect to $L$ and $x$ to obtain

$$
\frac{d^{2}(T(J))}{d L d x}=F^{\prime}-\mathcal{C}_{23}+\beta \varphi J_{12}+\left[-\mathcal{C}_{12}+\beta \varphi J_{11}\right] \frac{d H}{d x} .
$$

Differentiate the FOC $\mathcal{C}_{1}=\beta(1-\delta) J_{1}$ with respect to $x$ to obtain

$$
\frac{d H}{d x}=\frac{\beta(1-\delta) J_{12}-\mathcal{C}_{13}}{\mathcal{C}_{11}-\beta(1-\delta) J_{11}}
$$

Substitute this into (38) to obtain

$$
\frac{d^{2}(T(J))}{d L d x}=F^{\prime}-\mathcal{C}_{23}+\frac{\beta \varphi J_{12} \mathcal{C}_{11}+\mathcal{C}_{12} \mathcal{C}_{13}-\beta(1-\delta) J_{12} \mathcal{C}_{12}-\beta \varphi J_{11} \mathcal{C}_{13}}{\mathcal{C}_{11}-\beta(1-\delta) J_{11}}
$$

In the last term, the denominator is positive and larger than $\mathcal{C}_{11}$. In the numerator, all terms involving $J_{11}$ and $J_{12}$ are non-negative (due to (27), (28) and (30)); hence the numerator is greater than $\mathcal{C}_{12} \mathcal{C}_{13} \leq 0$. Therefore,

$$
\frac{d^{2}(T(J))}{d L d x} \geq F^{\prime}-\mathcal{C}_{23}+\frac{\mathcal{C}_{12} \mathcal{C}_{13}}{\mathcal{C}_{11}}
$$

which is non-negative under (33). Hence, $T(J)$ is supermodular. 


\section{Proof of Lemma A.2:}

From (25), (26), (27), (28) and (30) follows that

$$
\begin{aligned}
& \mathcal{C}_{12}=\frac{\mathcal{C}_{11} C_{12} m}{C_{11}}, \\
& \mathcal{C}_{13}=\frac{\mathcal{C}_{11} C_{13} m}{C_{11}} .
\end{aligned}
$$

Furthermore, substituting (28) into (25), and substituting (30) into (26) to eliminate $D^{\prime \prime}(m)$ imply that

$$
\begin{aligned}
& \mathcal{C}_{22}=C_{22}-\frac{C_{12}^{2}}{C_{11}}+\frac{m C_{12}}{C_{11}} \mathcal{C}_{12} \\
& \mathcal{C}_{23}=C_{23}-\frac{C_{12}}{C_{11}}\left[C_{13}-m \mathcal{C}_{13}\right]
\end{aligned}
$$

Part (a): Rewrite (32) using (40) and (42) to obtain the equivalent condition

$$
x F^{\prime \prime}-C_{22}+\frac{C_{12}^{2}}{C_{11}} \leq 0 .
$$

Because of $C_{11}>0$, this condition is equivalent to (34).

Part (b): Rewrite (33) using (40), (41) and (43) to obtain the equivalent condition

$$
F^{\prime}-C_{23}+\frac{C_{12} C_{13}}{C_{11}} \geq 0 .
$$

Because of $C_{11}>0$, this condition is equivalent to (35).

\section{Proof of Proposition 1 (continued):}

It follows from Lemma A.1 and A.2 that the value function $J(L, x)$ is concave in $L$ and supermodular in $(L, x)$ because property $(\mathrm{C})$ together with the assumption that $x F()-.C($.$) is concave in (L, V)$ guarantee both (34) and (35).

Because of strict concavity of problem (20), policy functions $m^{x}(L)$ and $V^{x}\left(m^{x}(L), L\right)$ exist. To derive first-order conditions (5) and (6) is straightforward: The first condition directly follows from (23); the second follows from the intertemporal optimality condition $\mathcal{C}_{1}(H, L, x)=\beta(1-\delta) J_{1}(L(1-s)+H, x)$ and from using the envelope theorem and (5).

The properties of $V^{x}$ stated in Proposition 1 were already established in the main text. To see how $m^{x}(L)$ depends on $L$, use (25) and (37) to get

$$
\frac{d m^{x}(L)}{d L}=\frac{d m(H, L, x)}{d L}+\frac{d m(H, L, x)}{d H} \frac{d H}{d L}=\frac{d m}{d H}\left[\frac{C_{12} m}{C_{11}}+\frac{\beta \varphi J_{11}-\mathcal{C}_{12}}{\mathcal{C}_{11}-\beta(1-\delta) J_{11}}\right] .
$$

Because of

$$
\frac{C_{12} m}{C_{11}}=\frac{\mathcal{C}_{12}}{\mathcal{C}_{11}} \leq \frac{\mathcal{C}_{12}}{\mathcal{C}_{11}-\beta(1-\delta) J_{11}},
$$

the term in [.] is negative, and so is $d m^{x} /(d L)$. 
To verify that $m$ is increasing in $x$, use (26) and (39) to get

$$
\frac{d m^{x}(L)}{d x}=\frac{d m(H, L, x)}{d x}+\frac{d m(H, L, x)}{d H} \frac{d H}{d x}=\frac{d m}{d H}\left[\frac{C_{13} m}{C_{11}}+\frac{\beta(1-\delta) J_{12}-\mathcal{C}_{13}}{\mathcal{C}_{11}-\beta(1-\delta) J_{11}}\right] .
$$

Because of

$$
\frac{C_{13} m}{C_{11}}=\frac{\mathcal{C}_{13}}{\mathcal{C}_{11}} \geq \frac{\mathcal{C}_{13}}{\mathcal{C}_{11}-\beta(1-\delta) J_{11}},
$$

the term in [.] is positive, and so is $d m^{x} /(d x)$.

Corollary 2: If recruitment costs are given by either specification in (1) with parameter $h$ sufficiently small, more productive firms have a higher growth rate, conditional on size; and larger/older firms have a lower growth rate, conditional on productivity.

\section{Proof of Corollary 2:}

Because of exogenous separations, the growth rate of a firm, $[m V-s L] / L$ is perfectly correlated with the job-creation rate,

$$
\operatorname{JCR}(x, L)=m^{x}(L) \frac{V^{x}\left(m^{x}(L), L\right)}{L} .
$$

Differentiation of the job-creation rate with respect to $x$ implies

$$
\frac{d \mathrm{JCR}}{d x}=\frac{d m^{x}}{d x} \frac{V^{x}}{L}+\frac{m^{x}}{L} \frac{d V^{x}}{d x}+\frac{m^{x}}{L} \frac{d V^{x}}{d m} \frac{d m^{x}}{d x} .
$$

In this expression, the first and the third term are strictly positive. Under the second cost function in (1), the second term is zero. Under the first cost function in (1), the second term is zero when $h=0$, and negative but small if $h$ is small. Thus, $d \mathrm{JCR} /(d x)$ is positive if $h$ is sufficiently small.

Differentiation of the job-creation rate with respect to $L$ implies

$$
\frac{d \mathrm{JCR}}{d L}=\frac{d m^{x}}{d L} \frac{V^{x}}{L}+\frac{m^{x}}{L} \frac{d V^{x}}{d L}+\frac{m^{x}}{L} \frac{d V^{x}}{d m} \frac{d m^{x}}{d L}-m \frac{V^{x}}{L^{2}} .
$$

In this expression, the first, the third and the fourth term are strictly negative. Under the second cost function in (1), $\frac{d V^{x}}{d L}=\frac{V^{x}}{L}$, and the second and forth terms cancel out. Under the first cost function in (1), the second term is zero when $h=0$, and positive but small if $h$ is small. Thus, $d \mathrm{JCR} /(d L)$ is negative if $h$ is sufficiently small.

Lemma A.3: In the stationary model with recruitment cost $C(V, L, x)=x F(L)-$ $x F(L-h V)+c V$, job-filling rates in the optimal firm's problem follow the dynamic equation

$$
\rho\left[m_{t+1} \lambda^{\prime}\left(m_{t+1}\right)-\lambda\left(m_{t+1}\right)\right]-(b+\rho) h-c=\frac{\rho h}{\beta(1-\delta)}\left[\lambda^{\prime}\left(m_{t}\right)-\beta \varphi \lambda^{\prime}\left(m_{t+1}\right)\right] .
$$

It has a unique steady state solution $m^{*}>0$ if, and only if,

$$
h<\frac{\beta(1-\delta) \bar{m}}{1-\beta \varphi}
$$


with $\bar{m} \equiv \lim _{m \rightarrow 1} m-\frac{\lambda(m)}{\lambda^{\prime}(m)}>0$. Under this condition, any sequence $m_{t}>0$ satisfying this dynamic equation converges to $m^{*}$.

\section{Proof of Lemma A.3:}

It is straightforward to derive (44) by substitution of (5) into (6). A steady state $m^{*}$ must satisfy the condition

$$
\rho\left[m-\frac{\lambda(m)}{\lambda^{\prime}(m)}\right]=\frac{\rho h(1-\beta \varphi)}{\beta(1-\delta)}+\frac{(b+\rho) h+c}{\lambda^{\prime}(m)} .
$$

The LHS is strictly increasing and goes from 0 to $\rho \bar{m}$ as $m$ goes from 0 to 1 . The RHS is decreasing in $m$ with limit $\rho h(1-\beta \varphi) /[\beta(1-\delta)]$ for $m \rightarrow 1$. Hence, a unique steady state $m^{*}$ exists iff (45) holds. ${ }^{42}$ Furthermore, differentiation of (44) at $m^{*}$ implies that

$$
\left.\frac{d m_{t+1}}{d m_{t}}\right|_{m^{*}}=\frac{h}{\beta(1-\delta) m^{*}+h \beta \varphi},
$$

which is positive and smaller than one iff

$$
h<\frac{\beta(1-\delta) m^{*}}{1-\beta \varphi} .
$$

But this inequality must be true because (46) implies

$$
h=\frac{\rho\left[m^{*} \lambda^{\prime}\left(m^{*}\right)-\lambda\left(m^{*}\right)\right]-c}{\frac{\rho(1-\beta \varphi \rho)}{\beta(1-\delta)} \lambda^{\prime}\left(m^{*}\right)+b+\rho}<\frac{\beta(1-\delta) m^{*}}{1-\beta \varphi} .
$$

Therefore, the steady state $m^{*}$ is locally stable. Moreover, the dynamic equation defines a continuous, increasing relation between $m_{t+1}$ and $m_{t}$ which has only one intersection with the 45-degree line. Hence, $m_{t+1}>m_{t}$ for any $m_{t}<m^{*}$ and $m_{t+1}<m_{t}$ for any $m_{t}>m^{*}$, which implies that $m_{t}$ converges to $m^{*}$ from any initial value $m_{0}>0$.

Proposition 2: A stationary competitive search equilibrium exists and is unique. There is strictly positive firm entry provided that $K$ is sufficiently small.

\section{Proof of Proposition 2:}

It remains to prove existence and uniqueness. From Proposition 1 follows that the entrant's value function $J^{x}(0,0)$ is decreasing and continuous in $\rho$. Hence the expected profit prior to entry,

$$
\Pi^{*}(\rho) \equiv \sum_{x \in X} \pi(x) J^{x}(0,0)
$$

is a decreasing and continuous function of $\rho$. Moreover, the function is strictly decreasing in $\rho$ whenever it is positive. This also follows from the proof of Proposition 1 which shows that $J(0, x ; \rho)$ is strictly decreasing in $\rho$ when the new firm $x$ recruits workers $\left(V^{x}\left(m^{x}(0), 0\right)>0\right)$. If no new firm recruits workers, expected profit of an

\footnotetext{
${ }^{42}$ If this condition fails, firms cannot profitably recruit workers.
} 
entrant cannot be positive. Hence, equation (7) can have at most one solution for any $K>0$. This implies uniqueness, with entry of firms if (7) can be fulfilled or without entry of firms otherwise. A solution to (7) exists provided that $K$ is sufficiently small. To see this, $\Pi^{*}(0)$ is strictly positive because of $F^{\prime}(0)=\infty$ : some entrants will recruit workers since the marginal product $J_{1}(m V, x ; \rho)$ is sufficiently large relative to the cost of recruitment and relative to the wage cost which are, for $\rho=0$, equal to $m V b$ (see equation (20)). But when $\Pi^{*}(0)>0$, a sufficiently small value of $K$ guarantees that (7) has a solution since $\lim _{\rho \rightarrow \infty} \Pi^{*}(\rho)=0$.

Proposition A.1: The stationary competitive search equilibrium is socially optimal. Proof of Proposition A.1:

The social planner decides at each point in time about firm entry, vacancy postings and job-filling rates for all firms. The planner takes as given the numbers of firms that entered in some earlier period, as well as the employment stocks of all these firms. Formally, the planner's state vector is $\sigma=\left(N_{a}, L_{a}^{x}\right)_{a \geq 1, x \in X}$ where $N_{a}$ is the mass of firms of age $a \geq 1$, and $L_{a}^{x}$ is employment of a firm with productivity $x$ and age $a$. The planner maximizes the present value of output net of opportunity costs of employment and net of the costs of entry and recruitment, subject to the economy's resource constraint. With $\sigma_{+}=\left(N_{a,+}, L_{a,+}^{x}\right)_{a \geq 1, x \in X}$ denoting the state vector in the next period, the recursive formulation of the social planning problem is

$$
\begin{aligned}
S(\sigma)= & \max _{N_{0},\left(V_{a}^{x}, m_{a}^{x}\right)_{a \geq 0}}\left\{\sum_{a \geq 0} N_{a} \sum_{x \in X} \pi(x)\left[x F\left(L_{a}^{x}\right)-b L_{a}^{x}-C\left(V_{a}^{x}, L_{a}^{x}, x\right)\right]\right\} \\
& -K N_{0}+\beta S\left(\sigma_{+}\right) \\
\text {s.t. } L_{0}^{x}=0, L_{a+1,+}^{x}=(1-s) L_{a}^{x}+m_{a}^{x} V_{a}^{x}, a \geq 0, x \in X, & N_{a+1,+}=(1-\delta) N_{a}, a \geq 0, \\
& \sum_{a \geq 0} N_{a} \sum_{x \in X} \pi(x)\left(L_{a}^{x}+\lambda\left(m_{a}^{x}\right) V_{a}^{x}\right) \leq 1 .
\end{aligned}
$$

We now show that the first-order conditions that uniquely characterize the decentralized allocation are also first order conditions to the planner's problem. The same argument that we use in the proof of Lemma A.4 part (b) (see the proof of Proposition 3) then establishes that the planner cannot improve upon this allocation. We denote by $S_{N, a}$ the derivative of $S$ with respect to $N_{a}$ and by $S_{L, a, x}$ the derivative of $S$ with respect to $L_{a}^{x}$. The multiplier on the resource constraint is $\mu \geq 0$. First-order conditions with respect to $N_{0}, V_{a}^{x}$, and $m_{a}^{x}, a \geq 0$, are

$$
\begin{array}{r}
\sum_{x \in X} \pi(x)\left[x F(0)-C\left(V_{0}^{x}, 0, x\right)\right]-K+\beta(1-\delta) S_{N, 1}-\mu \sum_{x \in X} \pi(x) \lambda\left(m_{0}^{x}\right) V_{0}^{x}=0 \\
-N_{a} \pi(x)\left[C_{1}\left(V_{a}^{x}, L_{a}^{x}, x\right)+\mu \lambda\left(m_{a}^{x}\right)\right]+\beta S_{L, a+1, x} m_{a}^{x} \leq 0, V_{a}^{x} \geq 0 \\
\beta S_{L, a+1, x}-\mu N_{a} \pi(x) \lambda^{\prime}\left(m_{a}^{x}\right)=0 .
\end{array}
$$


Here condition (49) holds with complementary slackness. The envelope conditions are, for $a \geq 1$ and $x \in X$,

$$
\begin{gathered}
S_{L, a, x}=N_{a} \pi(x)\left[x F^{\prime}\left(L_{a}^{x}\right)-C_{2}^{\prime}\left(V_{a}^{x}, L_{a}^{x}, x\right)-b-\mu\right]+\beta(1-s) S_{L, a+1, x} \\
S_{N, a}=\sum_{x \in X} \pi(x)\left[x F\left(L_{a}^{x}\right)-C\left(V_{a}^{x}, L_{a}^{x}, x\right)-b L_{a}^{x}\right]-\mu \sum_{x \in X} \pi(x)\left(L_{a}^{x}+\lambda\left(m_{a}^{x}\right) V_{a}^{x}\right)+\beta(1-\delta) S_{N, a+1} .
\end{gathered}
$$

Use (50) to substitute $S_{L, a, x}$ into (51) to obtain

$$
x F^{\prime}\left(L_{a+1}^{x}\right)-C_{2}\left(V_{a+1}^{x}, L_{a+1}^{x}, x\right)-b-\mu=\frac{\mu}{\beta(1-\delta)}\left[\lambda^{\prime}\left(m_{a}^{x}\right)-\beta \varphi \lambda^{\prime}\left(m_{a+1}^{x}\right)\right] .
$$

This equation is the planner's intertemporal optimality condition; it coincides with equation (6) for $\mu=\rho$. This is intuitive: when the social value of an unemployed worker $\mu$ coincides with the surplus value that an unemployed worker obtains in search equilibrium, the firm's recruitment policy is efficient. Next substitute (50) into (49) to obtain, for $a \geq 0$ and $x \in X$,

$$
C_{1}\left(V_{a}^{x}, L_{a}^{x}, x\right) \geq \mu\left[m_{a}^{x} \lambda^{\prime}\left(m_{a}^{x}\right)-\lambda\left(m_{a}^{x}\right)\right], V_{a}^{x} \geq 0 .
$$

Again for $\mu=\rho$, this condition coincides with the firm's intratemporal optimality condition in competitive search equilibrium, equation (5). Lastly, it remains to verify that entry is socially efficient when the value of a jobless worker is $\mu=\rho$. The planner's choice of firm entry, condition (48), together with the recursive equation for the marginal firm surplus $S_{N, a}$, equation (52), shows that

$$
K=\sum_{a \geq 0}[\beta(1-\delta)]^{a} \sum_{x \in X} \pi(x)\left[x F\left(L_{a}^{x}\right)-b L_{a}^{x}-C\left(V_{a}^{x}, L_{a}^{x}, x\right)-\mu\left(L_{a}^{x}+\lambda\left(m_{a}^{x}\right) V_{a}^{x}\right)\right] .
$$

On the other hand, the expected profit value of a new firm is

$$
\sum_{x \in X} \pi(x) J^{x}(0,0)=\sum_{a \geq 0}[\beta(1-\delta)]^{a} \sum_{x \in X} \pi(x)\left[x F\left(L_{a}^{x}\right)-W_{a}^{x}-C\left(V_{a}^{x}, L_{a}^{x}, x\right)\right] .
$$

Hence, the free-entry condition in search equilibrium, equation (7), coincides with condition (54) for $\mu=\rho$ if, for all $x \in X$,

$$
\sum_{a \geq 0}[\beta(1-\delta)]^{a}\left[(b+\mu) L_{a}^{x}+\mu \lambda\left(m_{a}^{x}\right) V_{a}^{x}-W_{a}^{x}\right]=0 .
$$


Now after substitution of

$$
\begin{aligned}
L_{a}^{x} & =\sum_{k=0}^{a-1}(1-s)^{a-1-k} m_{k}^{x} V_{k}^{x}, \text { and } \\
W_{a}^{x} & =\sum_{k=0}^{a-1}(1-s)^{a-1-k} V_{k}^{x}\left[\frac{\rho \lambda\left(m_{k}^{x}\right)(1-\beta \varphi)}{\beta(1-\delta)}+m_{k}^{x}(b+\rho)\right]
\end{aligned}
$$

into (55), it is straightforward to see that the equation is satisfied for $\mu=\rho$.

\section{Proposition 3:}

(a) Suppose that a solution of (14) and (15) exists with associated allocation $\mathbf{A}=$ $(\mathbf{N}, \mathbf{L}, \mathbf{V}, \mathbf{m}, \mathbf{s}, \boldsymbol{\delta})$ satisfying $N\left(z^{t}\right)>0$ for all $z^{t}$. Then $\mathbf{A}$ is a solution of the sequential planning problem (12).

(b) If $K(z), f$, and $b$ are sufficiently small and if $z_{1}=\ldots=z_{n}=\bar{z}$, equations (14) and (15) have a unique solution $(G, M)$. Moreover, if the transition matrix $\psi\left(z_{j} \mid z_{i}\right)$ is strictly diagonally dominant and if $\left|z_{i}-\bar{z}\right|$ is sufficiently small for all $i$, equations (14) and (15) have a unique solution.

\section{Proof of Proposition 3:}

Part (a):

Let $\beta^{t} \psi\left(z^{t}\right) \mu\left(z^{t}\right) \geq 0$ be the multiplier on the resource constraint (13) in history node $z^{t}$. That is, $\mu\left(z^{t}\right)$ is the social value of a worker in history $z^{t}$. Write $\boldsymbol{\mu}=\left(\mu\left(z^{t}\right)\right)$ for the vector of multipliers. Let $G_{t}\left(L, x, z^{t}\right)$ denote the social value of an existing firm with employment stock $L$, idiosyncratic productivity $x$ and aggregate productivity history $z^{t}$. The sequence $G_{t}$ obeys the recursive equations

$$
\begin{gathered}
G_{t}\left(L, x, z^{t}\right)=\max _{\delta, s, V, m} x z_{t} F(L)-b L-\mu\left(z^{t}\right)[L+\lambda(m) V]-C\left(V, L, x z_{t}\right)-f \\
+\beta(1-\delta) \mathrm{E}_{x, z^{t}} G_{t+1}\left(L_{+}, x_{+}, z^{t+1}\right) \\
\text { s.t. } \quad \begin{array}{l}
L_{+}=(1-s) L+m V, \\
\quad \delta \in\left[\delta_{0}, 1\right], s \in\left[s_{0}, 1\right], m \in[0,1], V \geq 0 .
\end{array}
\end{gathered}
$$

We first prove the equivalence between problem (56) and the planner's problem (12) (Lemma A.4). Then we show that the reduced problem (14) solves (56) if entry is positive in all states.

\section{Lemma A.4:}

(a) For given multipliers $\mu\left(z^{t}\right)$, there exist value functions $G_{t}: \mathbb{R}_{+} \times X \times Z^{t+1} \rightarrow \mathbb{R}$, $t \geq 0$, satisfying the system of recursive equations (56). 
(b) If $\mathbf{X}=(\mathbf{N}, \mathbf{L}, \mathbf{V}, \mathbf{m}, \mathbf{s}, \boldsymbol{\delta})$ is a solution of the planning problem (12) with multipliers $\boldsymbol{\mu}=\left(\mu\left(z^{t}\right)\right)$, then the corresponding firm policies also solve problem (56) and the complementary-slackness condition

$$
\sum_{x \in X} \pi_{0}(x) G_{t}\left(0, x, z^{t}\right) \leq K\left(z_{t}\right), N_{0}\left(z^{t}\right) \geq 0
$$

is satisfied for all $z^{t}$. Conversely, if $\mathbf{X}$ solves for every firm problem (56) with multipliers $\boldsymbol{\mu}$, and if condition (57) and the resource constraint (13) hold for all $z^{t}$, then $\mathbf{X}$ is a solution of the planning problem (12).

\section{Proof of Lemma A.4:}

Part (a): The RHS in the system of equations in (56) defines an operator $T$ which maps a sequence of bounded functions $G=\left(G_{t}\right)_{t \geq 0}$, with $G_{t}:[0, \bar{L}] \times X \times Z^{t} \rightarrow \mathbb{R}$ such that $\|G\| \equiv \sup _{t}\left\|G_{t}\right\|<\infty$, into another sequence of bounded functions $\tilde{G}=\left(\tilde{G}_{t}\right)_{t>0}$ with $\|\tilde{G}\|=\sup _{t}\left\|\tilde{G}_{t}\right\|<\infty$. Here $\bar{L}$ is sufficiently large such that the bound $L_{+} \leq \bar{L}$ does not bind for any $L \in[0, \bar{L}]$. The existence of $\bar{L}$ follows from the Inada condition for $F$ : the marginal product of an additional worker $x z F^{\prime}\left(L_{+}\right)-b$ must be negative for any $x \in X, z \in Z$, for all $L_{+} \geq \bar{L}$ with sufficiently large $\bar{L}$; hence no hiring will occur beyond $\bar{L}$. Because the operator satisfies Blackwell's sufficient conditions, it is a contraction in the space of bounded function sequences $G$. Hence, the operator $T$ has a unique fixed point which is a sequence of bounded functions.

Part (b): Take first a solution $\mathbf{X}$ of the planning problem, and write $\beta^{t} \psi\left(z^{t}\right) \mu\left(z^{t}\right) \geq 0$ for the multipliers on constraints (13). Then $\mathbf{X}$ maximizes the Lagrange function

$$
\begin{aligned}
\mathcal{L}= & \max \sum_{t \geq 0, z^{t}} \beta^{t} \psi\left(z^{t}\right)\left\{-K\left(z_{t}\right) N_{0}\left(z^{t}\right)+\sum_{a \geq 0, x^{a}} N\left(x^{a}, z^{t}\right)\left[x_{a} z_{t} F\left(L\left(x^{a}, z^{t}\right)\right)-b L\left(x^{a}, z^{t}\right)\right.\right. \\
& \left.\left.-f-C\left(V\left(x^{a}, z^{t}\right), L\left(x^{a}, z^{t}\right), x_{a} z_{t}\right)-\mu\left(z^{t}\right)\left[L\left(x^{a}, z^{t}\right)+\lambda\left(m\left(x^{a}, z^{t}\right)\right) V\left(x^{a}, z^{t}\right)\right]\right]\right\}
\end{aligned}
$$

For each individual firm, this problem is the sequential formulation of the recursive problem (56) with multipliers $\mu\left(z^{t}\right)$. Hence, firm policies also solve the recursive problem; furthermore, the maximum of the Lagrange function is the same as the sum of the social values of entrant firms plus the social values of firms which already exist at $t=0$, namely,

$$
\begin{aligned}
\mathcal{L}= & \max _{N_{0}(.)} \sum_{t, z^{t}} \beta^{t} \psi\left(z^{t}\right) N_{0}\left(z^{t}\right)\left[-K\left(z_{t}\right)+\sum_{x} \pi_{0}(x) G_{t}\left(0, x, z^{t}\right)\right] \\
& +\sum_{z \in Z} \psi\left(z^{0}\right) \sum_{a \geq 1, x^{a}} N\left(x^{a}, z^{0}\right) G_{0}\left(L\left(x^{a}, z^{0}\right), x_{a}, z^{0}\right) .
\end{aligned}
$$

This also proves that the complementary-slackness condition (57) describes optimal entry. 
To prove the converse, suppose that $\mathbf{X}$ solves for every firm the recursive problem (56) with given multipliers $\mu\left(z^{t}\right)$, and that (57) and the resource constraints (13) are satisfied. We prove that $\mathbf{X}$ also solves the original planning problem (12) subject to (13) by contradiction: Suppose that there is an allocation $\mathbf{X}^{\prime}$ is feasible for problem (12) under constraint (13) and strictly dominates $\mathbf{X}$. Write

$$
O\left(x^{a}, z^{t}\right) \equiv x_{a} z_{t} F\left(L\left(x^{a}, z^{t}\right)\right)-b L\left(x^{a}, z^{t}\right)-f-C\left(V\left(x^{a}, z^{t}\right), L\left(x^{a}, z^{t}\right), x_{a} z_{t}\right)
$$

for the net output created by firm $\left(x^{a}, z^{t}\right)$ in allocation $\mathbf{X}$ and write $O^{\prime}\left(x^{a}, z^{t}\right)$ for the same object in allocation $\mathbf{X}^{\prime}$. Further, write $S$ for the total surplus value in allocation $\mathbf{X}$ and write $S^{\prime}>S$ for the surplus value in allocation $\mathbf{X}^{\prime}$. Then

$$
\begin{aligned}
S^{\prime}= & \sum_{t \geq 0, z^{t}} \beta^{t} \psi\left(z^{t}\right)\left\{-K\left(z_{t}\right) N_{0}^{\prime}\left(z^{t}\right)+\sum_{a \geq 0, x^{a}} N^{\prime}\left(x^{a}, z^{t}\right) O^{\prime}\left(x^{a}, z^{t}\right)\right\} \\
= & \sum_{t \geq 0, z^{t}} \beta^{t} \psi\left(z^{t}\right)\left\{-K\left(z_{t}\right) N_{0}^{\prime}\left(z^{t}\right)+\mu\left(z^{t}\right)-\mu\left(z^{t}\right)+\sum_{a \geq 0, x^{a}} N^{\prime}\left(x^{a}, z^{t}\right) O^{\prime}\left(x^{a}, z^{t}\right)\right\} \\
\leq & \sum_{t \geq 0, z^{t}} \beta^{t} \psi\left(z^{t}\right)\left\{-K\left(z_{t}\right) N_{0}^{\prime}\left(z^{t}\right)+\mu\left(z^{t}\right)\right. \\
& \left.+\sum_{a \geq 0, x^{a}} N^{\prime}\left(x^{a}, z^{t}\right)\left[O^{\prime}\left(x^{a}, z^{t}\right)-\mu\left(z^{t}\right)\left(L^{\prime}\left(x^{a}, z^{t}\right)+\lambda\left(m^{\prime}\left(x^{a}, z^{t}\right)\right) V^{\prime}\left(x^{a}, z^{t}\right)\right)\right]\right\} \\
\leq & \sum_{t \geq 0, z^{t}} \beta^{t} \psi\left(z^{t}\right) N_{0}^{\prime}\left(z^{t}\right)\left[-K\left(z_{t}\right)+\sum_{x} \pi_{0}(x) G_{t}\left(0, x, z^{t}\right)\right] \\
& +\sum_{z \in Z} \psi\left(z^{0}\right) \sum_{a \geq 1, x^{a}} N\left(x^{a}, z^{0}\right) G_{0}\left(L\left(x^{a}, z^{0}\right), x_{a}, z^{0}\right)+\sum_{t, z^{t}} \beta^{t} \psi\left(z^{t}\right) \mu\left(z^{t}\right) \\
\leq & \sum_{t \geq 0, z^{t}} \beta^{t} \psi\left(z^{t}\right) N_{0}\left(z^{t}\right)\left[-K\left(z_{t}\right)+\sum_{x} \pi_{0}(x) G_{t}\left(0, x, z^{t}\right)\right] \\
& +\sum_{z \in Z} \psi\left(z^{0}\right) \sum_{a \geq 1, x^{a}} N\left(x^{a}, z^{0}\right) G_{0}\left(L\left(x^{a}, z^{0}\right), x_{a}, z^{0}\right)+\sum_{t, z^{t}} \beta^{t} \psi\left(z^{t}\right) \mu\left(z^{t}\right)=S .
\end{aligned}
$$

Here the first equality just adds and subtracts $\mu\left(z^{t}\right)$. The subsquent inequality follows from resource constraint (13). The second inequality follows since the discounted sum of surplus values for an individual firm which is of age $a$ at time $t$, namely

$$
\begin{aligned}
& \sum_{\tau \geq t} \beta^{\tau-t} \sum_{x^{a+\tau-t} z^{\tau}} \psi\left(z^{\tau} \mid z^{t}\right) \pi\left(x^{a+\tau-t} \mid x^{a}\right) \prod_{k=t}^{\tau-1}\left[1-\delta\left(x^{a+k-t}, z^{k}\right)\right] \\
& {\left[O^{\prime}\left(x^{a+\tau-t}, z^{\tau}\right)-\mu\left(z^{\tau}\right)\left[L^{\prime}\left(x^{a+\tau-t}, z^{\tau}\right)+\lambda\left(m^{\prime}\left(x^{a+\tau-t}, z^{\tau}\right)\right) V^{\prime}\left(x^{a+\tau-t}, z^{\tau}\right)\right]\right], }
\end{aligned}
$$

is bounded above $G_{t}\left(0, x_{0}, z_{t}\right)$ (for new firms, $a=0$ ) or by $G_{0}\left(L\left(x^{a}, z^{0}\right), x_{a}, z^{0}\right.$ ) (for 
firms of age $a>0$ existing at $t=0$ ) by definition of $G_{t}$. The third inequality follows from the complementary-slackness condition (57): either the term $-K\left(z_{t}\right)+$ $\sum_{x} \pi_{0}(x) G_{t}\left(0, x, z^{t}\right)$ is zero in which case the first summand is zero on both sides of the inequality; or it is strictly negative in which case $N_{0}\left(z^{t}\right)=0$ and $N_{0}^{\prime}\left(z^{t}\right) \geq 0$. The last equality follows from the definition of surplus value $S$ and the assumption that allocation $\mathbf{X}$ solves problem (56) at the level of each individual firm. This proves $S^{\prime} \leq S$ and hence contradicts the hypothesis $S^{\prime}>S$. This completes the proof of Lemma A.4.

\section{Proof of Proposition 3 (continued):}

To complete the proof of Prop. 3, part (a), let $\mu_{i}$ be the multiplier in aggregate state $z_{i}$, defined by (14) and (15), and write $M=\left(\mu_{1}, \ldots, \mu_{n}\right)$. With $\mu\left(z^{t}\right) \equiv \mu_{i}$ for $z_{t}=z_{i}$, the unique solution of (56) coincides with the one of (14), i.e. $G_{t}\left(L, x, z^{t}\right)=G(L, x, i ; M)$ for $z_{t}=z_{i}$, and also the firm-level policies coincide. If they give rise to an allocation $\mathbf{X}$ with positive entry in all aggregate states $z^{t},(15)$ implies that (57) holds for all $z^{t}$. Hence Lemma A.4(b) implies that $\mathbf{X}$ is a solution of the planning problem.

Part (b): Solving (14) in the stationary case $z=\bar{z}$ involves to find a single value function $G(L, x ; M)$. Application of the contraction mapping theorem implies that such a solution exists, is unique, and is continuous and non-increasing in $\mu \in \mathbb{R}$ and strictly decreasing in $\mu$ when $G()>$.0 .

Therefore, the function $\Gamma(\mu) \equiv \sum_{x} \pi_{0}(x) G(0, x ; \mu) \geq 0$ is continuous, strictly decreasing when positive, and zero for large enough $\mu$. Furthermore, when $f$ and $b$ are sufficiently small, $\Gamma(0)>0$; hence when $K>0$ is sufficiently small, there exists a unique $\bar{\mu} \geq 0$ satisfying equation (15).

In the stochastic case $z \in\left\{z_{1}, \ldots, z_{n}\right\}$ and for any given vector $M=\left(\mu_{1}, \ldots, \mu_{n}\right) \in R_{+}^{n}$, the system of recursive equations (14) has a unique solution $G(. ; M)$. Again this follows from the application of the contraction-mapping theorem. Furthermore, $G$ is differentiable in $M$, and all elements of the Jacobian $\left(d G(L, x, i ; M) /\left(d \mu_{j}\right)\right)_{i, j}$ are non-positive. The RHS of (14) defines an operator mapping a function $G(L, x, i ; M)$ with a strictly diagonally dominant Jacobian matrix $\left(d G(L, x, i ; M) /\left(d \mu_{j}\right)\right)_{i, j}$ into another function $\tilde{G}$ whose Jacobian matrix $\left(d \tilde{G}(L, x, i ; M) /\left(d \mu_{j}\right)\right)_{i, j}$ is diagonally dominant. This follows since the transition matrix $\psi\left(z_{j} \mid z_{i}\right)$ is strictly diagonally dominant and since all elements of $\left(d \tilde{G}(L, x, i ; M) /\left(d \mu_{j}\right)\right)$ have the same (non-positive) sign. Therefore, the unique fixed point has a strictly diagonally dominant Jacobian. Now suppose that $\left(z_{1}, \ldots, z_{n}\right)$ is close to $(\bar{z}, \ldots, \bar{z})$ and consider the solution $\mu_{1}=\ldots=\mu_{n}=\bar{\mu}$ of the stationary problem. Since the Jacobian matrix $\left(d G(0, x, i ; M) /\left(d \mu_{j}\right)\right)_{i, j}$ is strictly diagonally dominant, it is invertible. By the implicit function theorem, a unique solution $M$ to equation (15) exits.

For the proof of Proposition 4, see Appendix B. 


\section{Appendix B: Decentralization}

\section{The Workers' Search Problem}

Let $U\left(z^{t}\right)$ be the utility value of an unemployed worker in history $z^{t}$, and let $E\left(\mathcal{C}_{a}, x^{k}, z^{t}\right)$ be the utility value of a worker hired by a firm of age $a$ in contract $\mathcal{C}_{a}$ who is currently employed at that firm in history $x^{k}$, with $k>a$. The latter satisfies the recursive equation

$$
\begin{gathered}
E\left(\mathcal{C}_{a}, x^{k}, z^{t}\right)=w_{a}\left(x^{k}, z^{t}\right)+\beta\left\{\left(1-\varphi_{a}\left(x^{k}, z^{t}\right)\right) \mathrm{E}_{z^{t}} U\left(z^{t+1}\right)\right. \\
\left.+\varphi_{a}\left(x^{k}, z^{t}\right) \mathrm{E}_{x^{k}, z^{t}} E\left(\mathcal{C}_{a}, x^{k+1}, z^{t+1}\right)\right\}
\end{gathered}
$$

An unemployed worker searches for contracts which promise the highest expected utility, considering that more attractive contracts are less likely to sign. The worker observes all contracts $\mathcal{C}_{a}$ and he knows that the probability to sign a contract is $m / \lambda(m)$ when $m$ is the firm's matching probability at the offered contract. That is, potential contracts are parameterized by the tuple $\left(m, \mathcal{C}_{a}\right)$. Unemployed workers apply for those contracts where expected surplus is maximized:

$$
\rho\left(z^{t}\right)=\max _{\left(m, \mathcal{C}_{a}\right)} \frac{m}{\lambda(m)}\left(1-\delta\left(x^{a}, z^{t}\right)\right) \beta \mathrm{E}_{x^{a}, z^{t}}\left[E\left(\mathcal{C}_{a}, x^{a+1}, z^{t+1}\right)-U\left(z^{t+1}\right)\right] .
$$

The Bellman equation for an unemployed worker reads as

$$
U\left(z^{t}\right)=b+\rho\left(z^{t}\right)+\beta \mathrm{E}_{z^{t}} U\left(z^{t+1}\right) .
$$

\section{The Firms' Problem}

A firm of age $a$ in history $\left(x^{a}, z^{t}\right)$ takes as given the employment stocks of workers hired in some earlier period, $\left(L_{\tau}\right)_{\tau=0}^{a-1}$, as well as the contracts signed with these workers, $\left(\mathcal{C}_{\tau}\right)_{\tau=0}^{a-1}$. For the contracts to be consistent with the firm's constraints on exit and separations, the retention probabilities must satisfy $\varphi_{\tau}\left(x^{a}, z^{t}\right) \leq\left(1-s_{0}\right)\left(1-\delta_{0}\right)$. The firm chooses an actual exit probability $\delta \geq \delta_{0}$ and cohort-specific layoff probabilities $s_{\tau}$. For these probabilities to be consistent with separation probabilities specified in existing contracts, it must hold that $\delta \leq 1-\varphi_{\tau}\left(x^{a}, z^{t}\right)$ for all $\tau \leq a-1$, and $s_{\tau}=$ $1-\varphi_{\tau}\left(x^{a}, z^{t}\right) /(1-\delta)$ when $\delta<1$, with arbitrary choice of $s_{\tau}$ when $\delta=1$. The firm also decides new contracts $\mathcal{C}_{a}$ to be posted in $V$ vacancies with desired matching probability $m$. It is no restriction to presuppose that the firm offers only one type of contract. When $J_{a}$ is the value function of a firm of age $a$, the firm's problem is written as

$$
\begin{aligned}
J_{a}\left[\left(\mathcal{C}_{\tau}\right)_{\tau=0}^{a-1},\left(L_{\tau}\right)_{\tau=0}^{a-1}, x^{a}, z^{t}\right]= & \max _{\left(\delta, m, V, \mathcal{C}_{a}\right)} x_{a} z_{t} F(L)-W-C\left(V, L, x_{a} z_{t}\right) \\
& -f+\beta(1-\delta) \mathrm{E}_{x^{a}, z^{t}} J_{a+1}\left[\left(\mathcal{C}_{\tau}\right)_{\tau=0}^{a},\left(L_{\tau+}\right)_{\tau=0}^{a}, x^{a+1}, z^{t+1}\right]
\end{aligned}
$$




$$
\begin{array}{ll}
\text { s.t. } & L_{a+}=m V, m \in[0,1], V \geq 0, L_{\tau+}=L_{\tau} \frac{\varphi_{\tau}\left(x^{a}, z^{t}\right)}{1-\delta}, \tau \leq a-1, \\
& \delta \in\left[\delta_{0}, \min _{0 \leq \tau \leq a-1} 1-\varphi_{\tau}\left(x^{a}, z^{t}\right)\right], s_{0} \leq 1-\varphi_{\tau}\left(x^{a}, z^{t}\right) /(1-\delta), \\
& W=\sum_{\tau=0}^{a-1} w_{\tau}\left(x^{a}, z^{t}\right) L_{\tau}, L=\sum_{\tau=0}^{a-1} L_{\tau}, \\
& \rho\left(z^{t}\right)=\frac{m}{\lambda(m)}(1-\delta) \beta \mathrm{E}_{x^{a}, z^{t}}\left[E\left(\mathcal{C}_{a}, x^{a+1}, z^{t+1}\right)-U\left(z^{t+1}\right)\right] \text { if } m>0 .
\end{array}
$$

The last condition is the workers' participation constraint; it specifies the minimum expected utility that contract $\mathcal{C}_{a}$ must promise in order to attract a worker queue of length $\lambda(m)$ per vacancy.

Definition: A competitive search equilibrium is a list

$$
\left[U\left(z^{t}\right), E(.), \rho\left(z^{t}\right), \mathcal{C}_{a}\left(x^{a}, z^{t}\right), m\left(x^{a}, z^{t}\right), V\left(x^{a}, z^{t}\right), \delta\left(x^{a}, z^{t}\right), J_{a}(.), L_{\tau}\left(x^{a}, z^{t}\right), N\left(x^{a}, z^{t}\right), N_{0}\left(z^{t}\right)\right],
$$

for all $t \geq 0, a \geq 0, x^{a} \in X^{a+1}, z^{t} \in Z^{t+1}, 0 \leq \tau \leq a$, and for a given initial firm distribution, such that

(a) Firms' exit, hiring and layoff strategies are optimal. That is, $J_{a}$ is the value function and $\mathcal{C}_{a}(),. \delta(),. m($.$) , and V($.$) are the policy functions for problem$ (61)-(65).

(b) Employment evolves according to

$$
\begin{aligned}
& L_{\tau}\left(x^{a}, z^{t}\right)=L_{\tau}\left(x^{a-1}, z^{t-1}\right) \frac{\varphi_{\tau}\left(x^{a}, z^{t}\right)}{1-\delta\left(x^{a}, z^{t}\right)}, 0 \leq \tau \leq a-1, \\
& L_{a}\left(x^{a}, z^{t}\right)=m\left(x^{a}, z^{t}\right) V\left(x^{a}, z^{t}\right), a \geq 0 .
\end{aligned}
$$

(c) Firm entry is optimal. That is, the complementary slackness condition

$$
\sum_{x} \pi_{0}(x) J_{0}\left(x, z^{t}\right) \leq K\left(z_{t}\right), N_{0}\left(z^{t}\right) \geq 0
$$

holds for all $z^{t}$, and the number of firms evolves according to (9) and (11).

(d) Workers' search strategies are optimal, i.e. $(\rho, U, E)$ satisfy equations (58), (59) and (60).

(e) Aggregate resource feasibility; for all $z^{t}$,

$$
\sum_{a \geq 0, x^{a}} N\left(x^{a}, z^{t}\right)\left[\lambda\left(m\left(x^{a}, z^{t}\right)\right) V\left(x^{a}, z^{t}\right)+\sum_{\tau=0}^{a-1} L_{\tau}\left(x^{a}, z^{t}\right)\right]=1 .
$$


Proposition 4: A competitive search equilibrium is socially optimal.

Proof of Proposition 4:

The proof proceeds in two steps. First, substitute the participation constraint (65) into the firm's problem and make use of the contracts' recursive equations (58) to show that the firms' recursive profit maximization problem is identical to the maximization of the social surplus of a firm. Second, show that a competitive search equilibrium is socially optimal.

First, define the social surplus of a firm with history $\left(x^{a}, z^{t}\right)$ and with predetermined contracts and employment levels as follows:

$G_{a}\left[\left(\mathcal{C}_{\tau}\right)_{\tau=0}^{a-1},\left(L_{\tau}\right)_{\tau=0}^{a-1}, x^{a}, z^{t}\right] \equiv J_{a}\left[\left(\mathcal{C}_{\tau}\right)_{\tau=0}^{a-1},\left(L_{\tau}\right)_{\tau=0}^{a-1}, x^{a}, z^{t}\right]+\sum_{\tau=0}^{a-1} L_{\tau}\left[E\left(\mathcal{C}_{\tau}, x^{a}, z^{t}\right)-U\left(z^{t}\right)\right]$.

Using (58) and (60), the worker surplus satisfies

$E\left(\mathcal{C}_{\tau}, x^{a}, z^{t}\right)-U\left(z^{t}\right)=w_{\tau}\left(x^{a}, z^{t}\right)-b-\rho\left(z^{t}\right)+\beta \varphi_{\tau}\left(x^{a}, z^{t}\right) \mathrm{E}_{x^{a}, z^{t}}\left[E\left(\mathcal{C}_{\tau}, x^{a+1}, z^{t+1}\right)-U\left(z^{t+1}\right)\right]$.

Now substitute this equation and (61) into (68), and write

$$
\sigma \equiv\left[\left(\mathcal{C}_{\tau}\right)_{\tau=0}^{a-1},\left(L_{\tau}\right)_{\tau=0}^{a-1}, x^{a}, z^{t}\right] \text { and } \sigma_{+} \equiv\left[\left(\mathcal{C}_{\tau}\right)_{\tau=0}^{a},\left(L_{\tau+}\right)_{\tau=0}^{a}, x^{a+1}, z^{t+1}\right]
$$

with $L_{\tau+}$ as defined in (62) and $L=\sum_{\tau=0}^{a-1} L_{\tau}$, to obtain

$$
\begin{aligned}
G_{a}(\sigma)= & \max _{\delta, m, V, \mathcal{C}_{a}}\left\{x_{a} z_{t} F(L)-C\left(V, L, x_{a} z_{t}\right)-f-\sum_{\tau=0}^{a-1} L_{\tau} w_{\tau}\left(x^{a}, z^{t}\right)\right. \\
& \left.+\beta(1-\delta) \mathrm{E}_{x^{a}, z^{t}} J_{a+1}\left(\sigma_{+}\right)\right\}+\sum_{\tau=0}^{a-1} L_{\tau}\left[w_{\tau}\left(x^{a}, z^{t}\right)-b-\rho\left(z^{t}\right)\right. \\
& \left.+\beta \varphi_{\tau}\left(x^{a}, z^{t}\right) \mathrm{E}_{x^{a}, z^{t}}\left[E\left(\mathcal{C}_{\tau}, x^{a+1}, z^{t+1}\right)-U\left(z^{t+1}\right)\right]\right] \\
= & \max _{\delta, m, V, \mathcal{C}_{a}}\left\{x_{a} z_{t} F(L)-\left[b+\rho\left(z^{t}\right)\right] L-f-C\left(V, L, x_{a} z_{t}\right)+\beta(1-\delta) \mathrm{E}_{x^{a}, z^{t}} J_{a+1}\left(\sigma_{+}\right)\right. \\
& \left.+\beta \sum_{\tau=0}^{a-1} L_{\tau} \varphi_{\tau}\left(x^{a}, z^{t}\right) \mathrm{E}_{x^{a}, z^{t}}\left[E\left(\mathcal{C}_{\tau}, x^{a+1}, z^{t+1}\right)-U\left(z^{t+1}\right)\right]\right\} \\
= & \max _{\delta, m, V, \mathcal{C}_{a}}\left\{x_{a} z_{t} F(L)-b L-\rho\left(z^{t}\right)[L+\lambda(m) V]-f-C\left(V, L, x_{a} z_{t}\right)\right. \\
& +\beta(1-\delta) \mathrm{E}_{x^{a}, z^{t}} J_{a+1}\left(\sigma_{+}\right)
\end{aligned}
$$




$$
\begin{aligned}
& \left.+\beta(1-\delta) \sum_{\tau=0}^{a} L_{\tau_{+}} \mathrm{E}_{x^{a}, z^{t}}\left[E\left(\mathcal{C}_{\tau}, x^{a+1}, z^{t+1}\right)-U\left(z^{t+1}\right)\right]\right\} \\
= & \max _{\delta, m, V, \mathcal{C}_{a}}\left\{x_{a} z_{t} F(L)-b L-\rho\left(z^{t}\right)[L+\lambda(m) V]-f\right. \\
& \left.-C\left(V, L, x_{a} z_{t}\right)+\beta(1-\delta) \mathrm{E}_{x^{a}, z^{t}} G_{a+1}\left(\sigma_{+}\right)\right\} .
\end{aligned}
$$

Here maximization is always subject to (62) and (63), the third equation makes use of

$$
(1-\delta) L_{\tau+}=\varphi_{\tau}\left(x^{a}, z^{t}\right) L_{\tau},
$$

for $\tau \leq a-1$, and

$$
\rho\left(z^{t}\right) \lambda(m) V=\beta(1-\delta) L_{a+} \mathrm{E}_{x^{a}, z^{t}}\left[E\left(\mathcal{C}_{a}, x^{a+1}, z^{t+1}\right)-U\left(z^{t+1}\right)\right],
$$

and the last equation makes use of (68) for $G_{a+1}$. This shows that the firm solves a surplus maximization problem which is identical to the one of the planner specified in (56) provided that $\rho\left(z^{t}\right)=\mu\left(z^{t}\right)$ holds for all $z^{t}$, where $\mu$ is the social value of an unemployed worker as defined in the proof of Proposition 3. The only difference between the two problems is that the firm commits to cohort-specific separation probabilities, whereas the planner chooses in every period an identical separation probability for all workers (and he clearly has no reason to do otherwise). Nonetheless, both problems have the same solution: they are dynamic optimization problems of a single decision maker in which payoff functions are the same and the decision sets are the same. Further, time inconsistency is not an issue since there is no strategic interaction and since discounting is exponential. Hence solutions to the two problems, with respect to firm exit, layoffs and hiring strategies, are identical. In both problems the decision maker could discriminate between different cohorts in principal. Because such differential treatment does not raise social firm value, there is also no reason for competitive search to produce such an outcome. Nonetheless, there can be equilibrium allocations where different cohorts have different separation probabilities, but these equilibria must also be socially optimal because they maximize social firm value.

It remains to verify that competitive search gives indeed rise to socially efficient firm entry. When $\mu\left(z^{t}\right)=\rho\left(z^{t}\right), G_{0}\left(x, z^{t}\right)=J_{0}\left(x, z^{t}\right)$ as defined in (68) coincides with $G_{0}\left(0, x, z^{t}\right)$, as defined in (56). Hence, the free-entry condition (66) coincides with the condition for socially optimal firm entry (57). Because of aggregate resource feasibility (67), the planner's resource constraint (13) is also satisfied. Since the allocation of a competitive search equilibrium satisfies all the requirements of Lemma A.4(b), it is socially optimal. 


\section{Appendix C: Calibration and Computation}

\section{Calibration}

We choose the period length to be one week and set $\beta=0.999$ so that the annual interest rate is about 5 percent. We assume a CES matching function $m(\lambda)=\left(1+k \lambda^{-r}\right)^{-1 / r}$ (i.e. the inverse of the function $\lambda(m)$ used in the main text) and set the two parameters $k$ and $r$ to target a weekly job-finding rate of 0.129 and an elasticity of the job-finding rate with respect to the vacancy-unemployment ratio of 0.28 (Shimer (2005)). ${ }^{43}$ By choosing parameter $c$ of the recruitment technology (see below), we also target the (average) weekly job-filling rate at 0.3 , which corresponds to a monthly vacancy yield of 1.3 (Davis et al. (2013)). Since in steady state the unemployment-vacancy ratio equals the ratio between the job-filling rate and the job-finding rate, we calculate the parameters $k$ and $r$ to attain the two targets at $\lambda=0.3 / 0.129=2.326$.

The production technology is Cobb-Douglas with $x L^{\alpha}$ where the firm's idiosyncratic productivity $x=x_{0} x_{1}$ contains a time-invariant component $x_{0}$ and a transitory component $x_{1}$ (cf. Elsby and Michaels (2013)). The time-invariant component is drawn upon firm entry from one of five values $x_{0}^{i}, i=1, \ldots, 5$, with entry shares $\sigma^{i}$ where $\left(x_{0}^{i}, \sigma^{i}\right)$ are chosen to match the firm and employment shares within the five size classes 1-49, 50-249, 250-999, 1000-9999, and $\geq 10000$, where data targets are taken from the Business Dynamics Statistics (BDS) of the U.S. Census Bureau. The transitory component $x_{1}$ is drawn from one of five equidistant values in the range $[1-\bar{x}, 1+\bar{x}]$ and is redrawn every period with probability $\pi$. Parameters $\pi$ and $\bar{x}$ are chosen to match a monthly separation rate of 4.2 percent and the observation that about two thirds of employment is at firms with monthly employment growth rates in the range [-0.02, 0.02] (see Davis et al. (2010)). Firm exit is exogenous; that is, we set the operating cost to $f=0$ and choose exit probabilities specific for the five size classes $\delta^{i}, i=1, \ldots, 5$, to match annual firm exit rates from the BDS. Parameter $\alpha$ is set to 0.7 which gives rise to a labor share of roughly $2 / 3$. Given that all capital is fixed at the level of a firm, this consideration does not take into account variable capital investment at the firm level which would suggest a higher value of $\alpha$; see Appendix $\mathrm{D}$ for a robustness analysis regarding this parameter.

In the benchmark parameterization, we set unemployment income $b$ at 0.7 of the average wage which is similar to the calibrated values of non-market work chosen by Hall and Milgrom (2008) and Pissarides (2009). ${ }^{44}$ As mentioned in the main text, we also consider a much higher value of this parameter, namely 97.7 percent of the average wage which corresponds to the choice of Hagedorn and Manovskii (2008) and gives rise

\footnotetext{
${ }^{43}$ Note that there is no third parameter in the CES matching function since we require that $\lim _{\lambda \rightarrow \infty} m(\lambda)=1$.

${ }^{44}$ Hall and Milgrom (2008) calibrate the flow value of unemployment at 0.71 of productivity (0.73 of wages). Their value includes a reasonably low value of unemployment benefits $(0.25)$ and reflects some risk sharing within households.
} 
to much more amplification of aggregate shocks. ${ }^{45}$ For this parameterization, we recalibrate all other parameters to hit the same targets as in the benchmark calibration. ${ }^{46}$ The exogenous quit rate is set at $s_{0}=0.0048$ to match a monthly quit rate of 2 percent. The entry cost parameter $K$ can be normalized arbitrarily since all firm value functions (and thus the free-entry condition) are linearly homogeneous in the vector $(x, b, c, K)$. As mentioned in the main text, the recruitment technology has the form $c(V)=$ $\frac{c}{1+\gamma}\left(\frac{V}{L}\right)^{\gamma} V$, where we take a cubic function $(\gamma=2)$ for the benchmark calibration. When we compare the benchmark results with those for $\gamma=0.1$ and for $\gamma=8$, we recalibrate parameters $c$ and $b$ (equivalently, parameter $K$ ) to target the average unemployment-vacancy ratio $\lambda=2.326$ which gives rise to an average weekly job-filling rate of 0.3 and the same $b / w$ ratio as in the benchmark. ${ }^{47}$ We note that recruitment costs per hire are reasonably low for all three parameterizations (below $1 \%$ of quarterly earnings).

In our business cycle analysis, we choose the aggregate state process $z$ as described in the text and let the entry cost $K$ vary with the aggregate state which stabilizes the volatility of job creation at opening firms. Specifically, $K$ attains the values $(324.6,327.2,329.8,332.4,335.0)$ in the five productivity states in the calibration with $b / w \approx 0.7$. For $b / w \approx 0.977, K$ attains the values $(214.1,218.5,222.6,226.6,230.5)$.

To complement the cross-sectional results in the main text, Table 6 reports quarterly job creation and job destruction rates in four different size classes taken from the Business Employment Dynamics dataset of the Bureau of Labor Statistics. ${ }^{48}$ The model generates job creation and job destruction rates which are falling in firm size, which is qualitatively in line with the data. The relationship is less pronounced than in the data because we do not calibrate the transitory productivity processes separately for each size class. Negative relationships between size and job flows are also observed for entering and exiting firms.

\section{Computation}

To solve the model numerically, we implement the procedure as outlined in Section 2.3.1. Given the discrete sets of idiosyncratic states $x \in X$ and aggregate states $z \in Z$ and the corresponding Markov transition matrices, as well as a grid for employment $L$, we solve recursive problems (14) for a given initial guess of multipliers $\mu(z), z \in Z$, by value-function iteration. To make sure that the free-entry conditions (15) are satisfied, we adjust multipliers accordingly. This yields firm value functions $G(L, x, z)$, as well

\footnotetext{
${ }^{45}$ This alternative value of $b$ corresponds to 96.8 percent of the average (employmentweighted) marginal product and 68 percent of labor productivity.

${ }^{46}$ Deviating from Table 1 , we set $c=0.496, K=236.3$ (which follows from $b=0.1$ and the choice of $b / w \approx 0.977), \bar{x}=0.104,\left(x_{0}^{i}\right)=(.273, .585, .913,1.503,3.060),\left(\sigma^{i}\right)=$ $(99.07,0.80, .10, .025, .001), \pi=0.06$.

${ }^{47}$ Deviating from Table 1 , we set $c=0.04092, K=358.69$ for $\gamma=0.1$ and $c=1.274 \cdot 10^{9}$, $K=287.46$ for $\gamma=8$ (fixing $b=0.1$ throughout).

${ }^{48}$ The largest size class in this dataset are firms with 1000 or more workers. Hence, we merge the two largest size classes for the reported model statistics.
} 
Table 6: Firm size and quarterly job flows

\begin{tabular}{|l|cccc|}
\hline Size class & $1-49$ & $50-249$ & $250-999$ & $\geq 1000$ \\
\hline \hline Data & \multicolumn{4}{|c|}{} \\
\hline Job creation & 10.6 & 6.0 & 4.6 & 2.9 \\
Job destruction & 10.4 & 5.7 & 4.3 & 2.7 \\
Job creation (openings) & 3.0 & 0.3 & 0.1 & 0.01 \\
Job destruction (closings) & 2.9 & 0.4 & 0.2 & 0.02 \\
\hline \hline Model & \multicolumn{5}{|c}{} \\
\hline Job creation & 9.6 & 7.5 & 7.3 & 6.3 \\
Job destruction & 9.4 & 7.3 & 7.2 & 6.4 \\
Job creation (openings) & 0.6 & 0.02 & 0.0 & 0.0 \\
Job destruction (closings) & 2.1 & 0.3 & 0.2 & 0.0 \\
\hline
\end{tabular}

Notes: Data statistics are from the Business Employment Dynamics (1992-2011) of the Bureau of Labor Statistics. Model statistics are from a cross section of $4.9 \cdot 10^{6}$ firms for the benchmark calibration $(\gamma=2)$.

as policy functions $\lambda(L, x, z), V(L, x, z), s(L, x, z) .{ }^{49}$ Given the calibrated (exogenous) exit rates $\delta(x)$, this allows us to compute retention rates $\varphi(L, x, z)=(1-\delta(x))(1-$ $s(L, x, z))$.

For the particular decentralization with flat-wage contracts mentioned in the text, we use the following procedure for the calculation. A flat-wage contract offered to a new hire specifies the wage $w$ together with retention probabilities $\varphi(L, x, z)$ that are identical for all workers in firm $(L, x, z)$. In a recursive equilibrium, this allows us to rewrite the identities for worker value functions $E(w, L, x, z)$, unemployment values $U(z)$, and the search surplus $\rho(z)=\mu(z)$, given by (58), (59) and (60) as follows:

$$
\begin{aligned}
E(w, L, x, z)= & w+\beta\left\{(1-\varphi(L, x, z)) \mathrm{E}_{z} U\left(z_{+}\right)\right. \\
& \left.+\varphi(L, x, z) \mathrm{E}_{x, z} E\left(w, L_{+}, x_{+}, z_{+}\right)\right\} \\
\mu(z)= & \frac{m(\lambda(L, x, z))}{\lambda(L, x, z)}(1-\delta(z)) \beta \mathrm{E}_{x, z}\left[E\left(w, L_{+}, x_{+}, z_{+}\right)-U\left(z_{+}\right)\right], \\
U(z)= & b+\mu(z)+\beta \mathrm{E}_{z} U\left(z_{+}\right) .
\end{aligned}
$$

Here $L_{+}=L(1-s(L, x, z))+m(\lambda(L, x, z)) V(L, x, z)$ is next period's employment which follows from the firms' policy functions. Equation (71) defines the flat wage

\footnotetext{
${ }^{49}$ Deviating from the main text, we write firm policies in terms of worker-job ratios $\lambda$, so that matching rates $m(\lambda)$ follow from the matching function.
} 
$w=w^{*}(L, x, z)$ that firm $(L, x, z)$ offers to new hires. Subtracting (72) from (70) gives

$$
E(w, L, x, z)-U(z)=w-b-\mu(z)+\beta \varphi(L, x, z) \mathrm{E}_{x, z}\left[E\left(w, L_{+}, x_{+}, z_{+}\right)-U\left(z_{+}\right)\right] .
$$

It follows that

$$
E(w, L, x, z)-U(z)=A(L, x, z)(w-b)-B(L, x, z)
$$

where $A(L, x, z)$ and $B(L, x, z)$ are defined recursively by

$$
\begin{aligned}
& A(L, x, z)=1+\beta \varphi(L, x, z) \mathrm{E}_{x, z} A\left(L_{+}, x_{+}, z_{+}\right) \\
& B(L, x, z)=\mu(z)+\beta \varphi(L, x, z) \mathrm{E}_{x, z} B\left(L_{+}, x_{+}, z_{+}\right) .
\end{aligned}
$$

From (71) and (73), we can compute the wage $w=w^{*}(L, x, z)$ that firm $(L, x, z)$ offers to new hires:

$w^{*}(L, x, z)=b+\left\{\frac{\mu(z) \lambda(L, x, z)}{m(\lambda(L, x, z))(1-\delta(x)) \beta}+\mathrm{E}_{x, z} B\left(L_{+}, x_{+}, z_{+}\right)\right\} \frac{1}{\mathrm{E}_{x, z} A\left(L_{+}, x_{+}, z_{+}\right)}$.

For the model computation, we solve (74) and (75) simultaneously with $G(L, x, z)$ in the value-function iteration. This allows us to compute the flat wages $w^{*}(L, x, z)$ offered to new hires.

After we solve the model for the firms' policy functions, we can first simulate a stationary cross-section of firms (in the absence of aggregate productivity shocks). This is done by following a given number of entrant firms (according to their permanent productivity types and entry shares) along their lifecycles. Regarding business cycle dynamics, we start from a stationary firm distribution and follow those firms across time when aggregate shocks are active. The numbers of new entrants are determined each period residually so that all workers are either employed or search for work at any of the existing or entering firms. 


\section{Appendix D: Robustness}

We explore the robustness of the main calibration results regarding different parameter choices for unemployment income $b$ and for the returns-to-scale parameter $\alpha$. Departing from the benchmark calibration with cubic vacancy costs we consider two variations. First, we consider the alternative of setting unemployment income to 97.7 percent of average wages ( $68 \%$ of labor productivity), instead of 70 percent as in the benchmark. Second, relative to the benchmark with $\alpha=0.7$ which gives rise to a plausible labor share (with fixed capital at any individual firm) we consider the alternative of $\alpha=0.95$ which is more in line with a model where capital can be adjusted at the firm level. In both variations, parameters $c, \bar{x}$ and $\left(x_{0}^{i}\right)$ are readjusted so that the model hits the same calibration targets as in the benchmark calibration. ${ }^{50}$

Table 7 replicates Table 2 to show that both model variations are calibrated to match firm and employment shares in the five size classes. The bottom three rows show how the shares of younger firms are declining with firm size in the two versions. Relative to the benchmark calibration, the model with high production function elasticity generates considerably lower shares of very young firms in the larger size classes, which indicates slower firm growth for this parameterization.

Figure 6 shows that the cross-sectional behavior of vacancy rates, vacancy yields, hires rates and layoff rates is almost unchanged relative to the benchmark calibration. That is, irrespective of the parameter values for $b$ and $\alpha$, the model with cubic vacancy costs explains more than half of the cross-sectional variation in vacancy yields, although the vacancy yield curve for $\alpha=0.95$ (green/dotted curve) flattens out at firm growth above 20 percent relative to the benchmark calibration (blue/solid curve).

\footnotetext{
${ }^{50}$ The calibration with $\alpha=0.95$ requires $c=15.64, K=80.46$ (again $b=0.1$ and $b / w \approx 0.7$ ), $\bar{x}=0.11,\left(x_{0}^{i}\right)=(.164, .184, .198, .218, .245),\left(\sigma^{i}\right)=(98.82,1.00, .153, .025, .002), \pi=0.027$. Parameters for the the version with $b / w \approx 0.977$ are stated in footnote 46 .
} 
Table 7: Firm size and employment distribution (higher values of $b$ and $\alpha$ )

\begin{tabular}{|l|ccccc|}
\hline Size class & $1-49$ & $50-249$ & $250-999$ & $1000-9999$ & $\geq 10000$ \\
\hline \hline Data & \multicolumn{5}{|c|}{} \\
\hline Firm shares & 95.62 & 3.64 & 0.54 & 0.17 & 0.02 \\
Employment shares & 29.31 & 16.23 & 10.88 & 17.64 & 25.93 \\
\% younger than 2 yrs. & 24.68 & 7.24 & 4.38 & 2.26 & 1.08 \\
\% younger than 5 yrs. & 39.71 & 16.88 & 10.19 & 5.35 & 3.65 \\
\% younger than 10 yrs. & 57.76 & 31.30 & 20.23 & 12.01 & 7.14 \\
\hline \hline Model (high $b$ ) & \multicolumn{5}{|c}{} \\
\hline Firm shares & 95.78 & 3.42 & 0.61 & 0.17 & 0.02 \\
Employment shares & 30.65 & 15.87 & 12.62 & 18.20 & 22.67 \\
\% younger than 2 yrs. & 16.19 & 3.62 & 2.55 & 2.26 & 1.79 \\
\% younger than 5 yrs. & 35.62 & 9.17 & 6.82 & 6.06 & 4.91 \\
\% younger than 10 yrs. & 58.44 & 17.91 & 13.90 & 12.40 & 10.13 \\
\hline \hline Model (high $\alpha$ ) & \multicolumn{5}{|c}{} \\
\hline Firm shares & 96.27 & 3.06 & 0.50 & 0.15 & 0.02 \\
Employment shares & 29.23 & 16.36 & 11.60 & 18.27 & 24.53 \\
\% younger than 2 yrs. & 16.13 & 1.65 & 1.30 & 0.95 & 0.42 \\
\% younger than 5 yrs. & 35.41 & 6.79 & 5.75 & 4.78 & 3.50 \\
\% younger than 10 yrs. & 58.12 & 15.28 & 12.24 & 11.66 & 7.59 \\
\hline
\end{tabular}

Notes: The top two rows report firm and employment shares in five size classes (calibrated). The bottom rows are the shares of younger firms in these classes. Data statistics are from the Business Dynamics Statistics of the Census Bureau for the year 2005. Model statistics are from a cross section of $4.9 \cdot 10^{6}$ firms. The model with high $b$ has $b \approx 0.977 w, \gamma=2, \alpha=0.7$, and the model with high $\alpha$ has $b \approx 0.7 w, \gamma=2, \alpha=0.95$. 

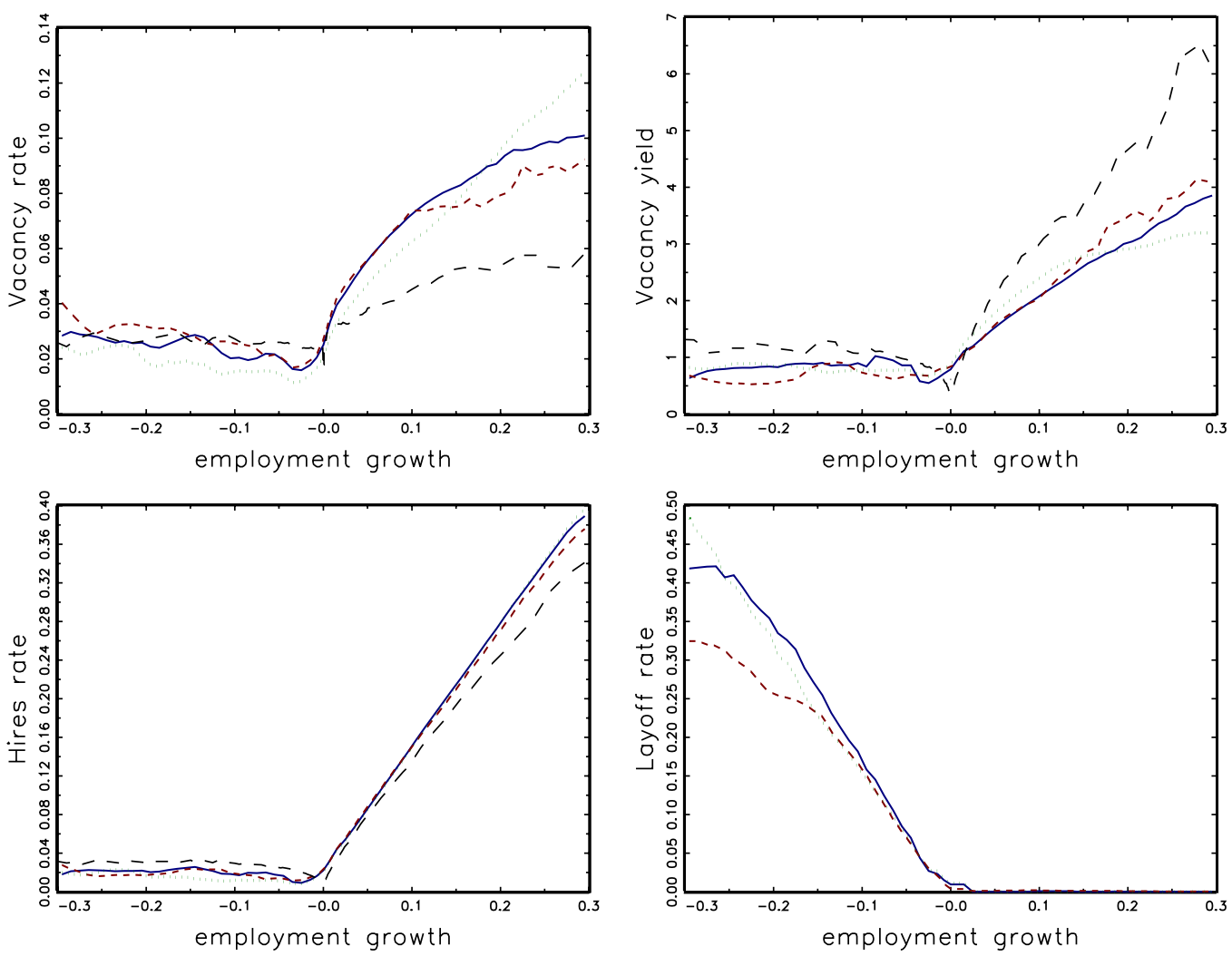

Figure 6: Cross-sectional relationships between monthly employment growth and the vacancy rate, the vacancy yield, the hires rate and the layoff rate. The dashed curves (in the first three graphs) are from the data used in Davis et al. (2013), the blue (solid) curves are for the benchmark parameterization $(b / w \approx 0.7, \alpha=0.7)$, the red (closely dashed) curves are for the calibration with $b / w \approx 0.977$ and the green (dotted) curves are for $\alpha=0.95$. 


\section{Appendix E: Impulse response in a VAR model}

We borrow the methodology for constructing the impulse responses in Figure 4 straight from Fujita and Ramey (2007) - except for the details discussed below. ${ }^{51}$ We use data from 1951:Q1 to 2011:Q4. The data is real quarterly GDP from FRED; the number of vacancies is from the Help Wanted Index from Barnichon's Composite Help-Wanted Index series; ${ }^{2}$ the number of unemployed is from the CPS; employment is from the BLS total payroll employment; and population is from the BLS. The job-finding rate is then calculated in the same way as in Elsby, Michaels, Solon (2009). ${ }^{53}$ All data other than GDP are averaged over their monthly (seasonally adjusted) observations to obtain quarterly series. They are then logged and detrended by regressing each on a cubic polynomial in time.

To generate impulse responses of output, employment, labor market tightness and the job-finding rate to a permanent rise in productivity, we first identify exogenous productivity deviations in the data series and look at how the variables of interest respond to these. Let

$$
\begin{aligned}
p_{t} & \equiv \text { observed (detrended) output per worker } \\
\theta_{t} & \equiv \text { observed (detrended) vacancy-unemployment ratio } \\
e_{t} & \equiv \text { observed (detrended) employment-population ratio } \\
\phi_{t} & \equiv \text { observed (detrended) job-finding rate }
\end{aligned}
$$

and let $z_{t}$ be the unobserved exogenous productivity deviation. To identify $z_{t}$, we first estimate (by OLS) the following system:

$$
\begin{aligned}
\ln p_{t} & =\left[\begin{array}{llll}
\ln p_{t} & \ln \theta_{t} & \ln e_{t} & \ln \phi_{t}
\end{array}\right]\left[\begin{array}{ccc}
A_{11} & A_{12} & A_{13} \\
A_{21} & A_{22} & A_{23} \\
A_{31} & A_{32} & A_{33} \\
A_{41} & A_{42} & A_{43}
\end{array}\right]\left[\begin{array}{c}
L \\
L^{2} \\
L^{3}
\end{array}\right]+\varepsilon_{t}^{p} \\
& =\left[\begin{array}{llll}
\ln p_{t} & \ln \theta_{t} & \ln e_{t} & \ln \phi_{t}
\end{array}\right] A(L)+\varepsilon_{t}^{p}
\end{aligned}
$$

where $L$ is the lag operator. Given this estimation, $\left\{\hat{A}_{i j}\right\}$, we follow Fujita and Ramey (2007) by assuming that the exogenous productivity deviations, ln $z_{t}$, can be identified

\footnotetext{
${ }^{51}$ We are grateful to David Ratner for providing an initial code.

${ }^{52}$ R. Barnichon, "Building a Composite Help-Wanted Index", Economics Letters, Vol. 109, 175-178, 2010.

${ }^{53}$ M. Elsby, R. Michaels and G. Solon, "The Ins and Outs of Cyclical Unemployment", American Economic Journal: Macroeconomics, Vol. 1, 84-110, 2009.
} 
by

$$
\begin{aligned}
& \ln p_{t<0}=\ln \theta_{t<0}=\ln e_{t<0}=\ln \phi_{t<0}=\ln z_{t<0}=0, \\
& \hat{\varepsilon}_{t}^{p}=\ln p_{t}-\left[\begin{array}{llll}
\ln p_{t} & \ln \theta_{t} & \ln e_{t} & \ln \phi_{t}
\end{array}\right] \hat{A}(L), \\
& \ln z_{t}=\hat{A}_{11} \ln z_{t-1}+\hat{A}_{12} \ln z_{t-2}+\hat{A}_{13} \ln z_{t-3}+\hat{\varepsilon}_{t}^{p} \text {. }
\end{aligned}
$$

Once a series for $\ln z_{t}$ has been identified from the data in this way, an $A R(3)$ process for $\ln z_{t}$ can be estimated,

$$
\begin{aligned}
\ln z_{t} & =C_{01} \ln z_{t-1}+C_{02} \ln z_{t-2}+C_{03} \ln z_{t-3}+\varepsilon_{t}^{z} \\
& =C_{0}(L) \ln z_{t}+\varepsilon_{t}^{z},
\end{aligned}
$$

and the relationship between the endogenous variables $\ln e_{t}, \ln \theta_{t}, \ln \phi_{t}$ and the exogenous process $\ln z_{t}$ can be calculated by estimating the following relationships (by OLS):

$$
\begin{aligned}
\ln e_{t}= & {\left[\begin{array}{lll}
\ln e_{t} & \ln \theta_{t} & \ln \phi_{t}
\end{array}\right]\left[\begin{array}{lll}
B_{111} & B_{112} & B_{113} \\
B_{121} & B_{122} & B_{123} \\
B_{131} & B_{132} & B_{133}
\end{array}\right]\left[\begin{array}{c}
L \\
L^{2} \\
L^{3}
\end{array}\right]+C_{1}(L) \ln z_{t}+D_{1} \hat{\varepsilon}_{t}^{p}+\varepsilon_{t}^{e} } \\
= & {\left[\begin{array}{lll}
\ln e_{t} & \ln \theta_{t} & \ln \phi_{t}
\end{array}\right] B_{1}(L)+C_{1}(L) \ln z_{t}+D_{1} \hat{\varepsilon}_{t}^{p}+\varepsilon_{t}^{e}, } \\
& \ln \theta_{t}=\left[\begin{array}{lll}
\ln e_{t} & \ln \theta_{t} & \ln \phi_{t}
\end{array}\right] B_{2}(L)+C_{2}(L) \ln z_{t}+D_{2} \hat{\varepsilon}_{t}^{p}+\varepsilon_{t}^{\theta}, \\
& \ln \phi_{t}=\left[\begin{array}{lll}
\ln e_{t} & \ln \theta_{t} & \ln \phi_{t}
\end{array}\right] B_{3}(L)+C_{3}(L) \ln z_{t}+D_{3} \hat{\varepsilon}_{t}^{p}+\varepsilon_{t}^{\phi} .
\end{aligned}
$$

The impulse-response functions to a permanent increase in exogenous productivity of $1 \%$ are then constructed by simulating these estimated relationships forward:

$$
\begin{aligned}
& \ln z_{t<0}=\ln e_{t<0}=\ln \theta_{t<0}=\ln \phi_{t<0}=0, \\
& \ln z_{t \geq 0}=0.01 \text {, } \\
& \hat{\varepsilon}_{t \geq 0}^{p}=\hat{\varepsilon}_{t \geq 0}^{z}=\ln z_{t \geq 0}-\hat{C}_{0}(L) \ln z_{t \geq 0}, \\
& \hat{\varepsilon}_{t}^{e}=\hat{\varepsilon}_{t}^{\theta}=\hat{\varepsilon}_{t}^{\phi}=0 \text {, } \\
& \ln e_{t}=\left[\begin{array}{lll}
\ln e_{t} & \ln \theta_{t} & \ln \phi_{t}
\end{array}\right] \hat{B}_{1}(L)+\hat{C}_{1}(L) \ln z_{t}+\hat{D}_{1} \hat{\varepsilon}_{t}^{p}, \\
& \ln \theta_{t}=\left[\begin{array}{lll}
\ln e_{t} & \ln \theta_{t} & \ln \phi_{t}
\end{array}\right] \hat{B}_{2}(L)+\hat{C}_{2}(L) \ln z_{t}+\hat{D}_{2} \hat{\varepsilon}_{t}^{p}, \\
& \ln \phi_{t}=\left[\begin{array}{lll}
\ln e_{t} & \ln \theta_{t} & \ln \phi_{t}
\end{array}\right] \hat{B}_{3}(L)+\hat{C}_{3}(L) \ln z_{t}+D_{3} \hat{\varepsilon}_{t}^{p} \text {, } \\
& \ln p_{t}=\left[\begin{array}{llll}
\ln p_{t} & \ln \theta_{t} & \ln e_{t} & \ln \phi_{t}
\end{array}\right] \hat{A}(L)+\hat{\varepsilon}_{t}^{p} .
\end{aligned}
$$


Our construction differs from Fujita and Ramey (2007) only in that their estimations are based on data to 2005, they use three variables $\left(p_{t}, \theta_{t}, e_{t}\right)$ for the VAR, and they show impulse responses for a one-time rather than a permanent shock. We replicated their settings and find their results, and we checked that adding the fourth variable does not qualitatively change the outcome for the three initial variables in their methodology. 